\title{
Effect of varying the Mg with Ca content in highly
}

\section{porous phosphate-based glass microspheres}

Md Towhidul Islam ${ }^{a, d \neq}$, Laura Macri-Pellizzeri ${ }^{b \neq}$, Kazi M. Zakir Hossain ${ }^{c}$, Virginie Sottile $^{b, e}$ and Ifty

$$
\text { Ahmed }{ }^{a *}
$$

${ }^{a}$ Advanced Materials Research Group, Faculty of Engineering, University of Nottingham, Nottingham, NG7 2RD, UK

${ }^{b}$ Wolfson STEM Centre, Division of Cancer and Stem Cells, School of Medicine, University of Nottingham, Nottingham NG7 2UH, UK

c Department of Chemistry, Faculty of Science, University of Bath, Bath, BA2 7AY, UK

${ }^{d}$ Department of Applied Chemistry and Chemical Engineering, Faculty of Engineering, Noakhali Science and Technology University, Noakhali-3814, Bangladesh

e Department of Molecular Medicine, The University of Pavia, 27100 Pavia, Italy

\section{Corresponding Author}

*email: Ifty.Ahmed@nottingham.ac.uk

\section{Author Contributions}

‡ M.T. Islam and L. Macri-Pellizzeri contributed equally to this work as first authors. 


\section{ABSTRACT}

This paper reports on the role of phosphate-based glass (PBG) microspheres and their physicochemical properties including in vitro biological response to human mesenchymal stem cells (hMSCs). Solid and porous microspheres were prepared via a flame spheroidisation process. The Mg content in the PBG formulations explored was reduced from 24 to $2 \mathrm{~mol} \%$ with a subsequent increase in $\mathrm{Ca}$ content. A small quantity of $\mathrm{TiO}_{2}(1 \mathrm{~mol} \%)$ was added to the lower $\mathrm{Mg}$ content glass ( 2 mol\%) to avoid crystallisation. Morphological and physical characterisation of porous microspheres revealed interconnected porosity (up to $76 \pm 5 \%$ ), average external pore sizes of $55 \pm 5 \mu \mathrm{m}$ with surface areas ranging from 0.38 to $0.43 \mathrm{~m}^{2} \mathrm{~g}^{-1}$. Degradation and ion release studies conducted compared the solid (non-porous) and porous microspheres and revealed 1.5 to 2.5 times higher degradation rate for porous microspheres. Also, in vitro bioactivity studies using simulated body fluid (SBF) revealed $\mathrm{Ca} / \mathrm{P}$ ratios for porous microspheres of all three glass formulations were between 0.75 and 0.92 which were within the range suggested for precipitated amorphous calcium phosphate. Direct cell seeding and indirect cell culture studies (via incubation with microsphere degradation products) revealed hMSCs were able to grow and undergo osteogenic differentiation in vitro, confirming cytocompatibility of the formulations tested. However, the higher $\mathrm{Mg}$ content (24 mol\%) porous microsphere showed the most potent osteogenic response and is therefore considered as a promising candidate for bone repair applications.

KEYWORDS: Porous microspheres, bioactivity, cytocompatibility, osteogenic differentiation, thermal properties, degradation, ion release 


\section{INTRODUCTION}

Phosphate based glasses (PBGs) have attracted much interest in the field of biomaterials and tissue engineering due to their controllable properties including degradation profiles, composition and more recently morphologies. PBGs have been manufactured to mimic the composition of inorganic bone and are therefore considered promising materials for bone regeneration as they can release ions into the local environment to enhance the regeneration process and provide structural support to the target tissue [1-5].

These unique glasses have been produced in varying geometries including particles, discs [4, 69], fibres [10-16] and more recently as microspheres $[17,18]$. In particular, microspheres have some key advantages for use in biomedical applications over irregular-shaped particles [19] including improved flow properties and superior packing densities, especially if bimodal particles size distributions are employed $[20,21]$. As such, they are highly beneficial for minimally invasive injection and implantation delivery routes, thus offering significant advantages for patient treatment and recovery.

Microspheres produced from varying materials (i.e. polymers, glasses, ceramics, etc) have been fabricated with either external or internal porosity, a combination of both and with or without interconnectivity [22]. Porous microspheres are hugely advantageous as they exhibit greater surface area and lower mass density, and thus can be exploited to confer control over their degradation profiles and ion release rates, especially from PBGs [23].

Glass, glass-ceramic and ceramic based microspheres have mainly been investigated for bone tissue regeneration, other orthopaedic applications including dental applications as well as for radiotherapy [22]. However, further applications can be derived from the use of porous 
microspheres depending on their composition and pore structure including level of porosity, pore sizes, surface area and interconnectivity. For example, one key advantage is that they can enable encapsulation of other biologically relevant entities (such as drugs, proteins, growth factors or cells) [22-25]. In addition, porous microspheres can be utilised as either stand-alone products or assembled into three-dimensional (3D) porous scaffolds $[23,25,26]$.

Several research groups have explored porous microspheres for bone tissue engineering or as carriers for drug delivery [25, 27, 28]. For example, Li et al. developed porous-wall hollow glass microspheres from sodium borosilicate glasses (between 20-40 $\mu \mathrm{m}$ ) with pore sizes ranging from 10-300 nm utilizing a controlled gas-air flame followed by sintering and leaching processes [25]. They also suggested possible applications for these microspheres in drug delivery, which would depend on successfully incorporating drugs inside them [25]. Bioactive microspheres (within the $\mathrm{SiO}_{2}-\mathrm{CaO}-\mathrm{P}_{2} \mathrm{O}_{5}$ system) with ordered mesoporous structure (i.e. with pore sizes from $0.5-40 \mathrm{~nm}$ ) were synthesized by Arcos et al. via an evaporation-induced self-assembly (EISA) method following an aerosol-assisted route for bone grafting and drug delivery applications [27].

Glass microspheres (i.e. solid non-porous and porous) can be produced through varying processing techniques such as sol-gel, tube furnace and more recently flame spheroidisation [22], a process shown to be relatively very fast, inexpensive and easily scalable for commercialisation purposes [19].

This study reports on the manufacture of three PBG formulations produced with variation of $\mathrm{MgO}$ content (from 2 to $24 \mathrm{~mol} \%$ ) as solid non-porous (SGMS) and porous microspheres (PGMS) in the system $40 \mathrm{P}_{2} \mathrm{O}_{5}-(24-\mathrm{x}) \mathrm{MgO}-(16+\mathrm{x}) \mathrm{CaO}-(20-\mathrm{y}) \mathrm{Na}_{2} \mathrm{O}-\mathrm{yTiO}{ }_{2}$ (where $0 \leq x \leq 22$ and $\mathrm{y}=0$ or 1 ). The characterization studies focused on their thermo-physical properties, degradation rates, ion 
release profiles and in vitro bioactivity via SBF studies. Moreover, porous microspheres from these PBG formulations were tested in vitro, using human mesenchymal precursor cells as a clinically relevant cell type. Indirect and direct cell culture systems were tested to evaluate the materials' ability to support cell growth and osteogenic potential.

\section{MATERIALS AND METHODOLOGY}

\section{Glass formulation preparation}

Three phosphate-based glass formulations in the series $40 \mathrm{P}_{2} \mathrm{O}_{5}-(40-\mathrm{x}) \mathrm{CaO}-\mathrm{xMgO}-(20-\mathrm{y}) \mathrm{Na}_{2} \mathrm{O}-$ $\mathrm{yTiO}_{2}$ (where $0 \leq x \leq 24$ and $y=0$ or 1 ) were prepared using sodium dihydrogen phosphate $\left(\mathrm{NaH}_{2} \mathrm{PO}_{4}\right)$, calcium hydrogen phosphate $\left(\mathrm{CaHPO}_{4}\right)$, magnesium hydrogen phosphate trihydrate $\left(\mathrm{MgHPO}_{4} \cdot 3 \mathrm{H}_{2} \mathrm{O}\right)$, phosphorous pentoxide $\left(\mathrm{P}_{2} \mathrm{O}_{5}\right)$ and titanium dioxide $\left(\mathrm{TiO}_{2}\right)$ as starting materials (Sigma Aldrich, UK), as described elsewhere [29]. Required amounts of precursors were placed into a platinum rhodium alloy crucible (Birmingham Metal Company, U.K.) and dried at $350^{\circ} \mathrm{C}$ for 30 mins. The mixture was then melted at $1150-1200^{\circ} \mathrm{C}$ for $1.5-2$ hours depending on the glass composition and poured onto a steel plate and left to cool to room temperature (see Table $\mathbf{1}$ for formulations produced).

\section{Manufacturing solid and porous phosphate glass microspheres}

The three PBG glass formulations (see Table 1) were then processed into solid glass microspheres (SGMS) and porous glass microspheres (PGMS) for further analysis as follows. The glasses made were ground using a ball mill (Retsch PM 100) and sieved into the particle size range of 63-125 $\mu \mathrm{m}$ and $125-200 \mu \mathrm{m}$. The particles in the size range of $125-200 \mu \mathrm{m}$ were then processed utilising 
a flame spheroidisation process to prepare solid microspheres, which utilised an oxy/acetylene flame spray gun (MK 74, Metallisation Ltd, UK) [19].

To manufacture porous microspheres, glass particles in the size range of 63-125 $\mu \mathrm{m}$ were mixed with porogen (i.e. calcium carbonate) at 1:3 ratio and processed via flame spheroidisation same as above to prepare solid glass microspheres [19]. The porous phosphate glass microspheres were then washed using acetic acid ( $5 \mathrm{M})$ for 2 mins followed by washing with deionised water for 5 mins and then dried at $50{ }^{\circ} \mathrm{C}$ overnight. The resulting porous glass microspheres were then sieved again and microspheres in the size range of $125-200 \mu \mathrm{m}$ were utilised for further studies.

\section{CHARACTERISATION METHODS}

\section{Scanning electron microscopy (SEM) and energy dispersive X-ray (EDX) analysis}

The surface morphology of both SGMS and PGMS microspheres were qualitatively examined via scanning electron microscopy (Philips XL 30 SEM, UK) operated at $15 \mathrm{kV}$ with working distance of $10 \mathrm{~mm}$. The quantitative compositional analysis of each formulation, before and after spheroidisation of the glass particles was carried out using energy dispersive X-ray (EDX) analysis. The glass microspheres were coated with carbon using an evaporation coater (Edwards coating System E306A).

\section{X-ray diffraction}

X-ray diffraction was performed to confirm the amorphous nature of each glass formulation of solid and porous microspheres using a Bruker D8 Advanced diffractometer. The instrument was operated at room temperature and ambient atmosphere with $\mathrm{Ni}$-filtered CuK $\alpha$ radiation 
$(\lambda=0.15418 \mathrm{~nm})$, generated at $40 \mathrm{kV}$ and $35 \mathrm{~mA}$. Scans were performed with a step size of $0.04^{\circ}$ and step time of $8 \mathrm{~s}$ over an angular range $2 \theta$ from $5^{\circ}$ to $50^{\circ}$.

\section{Density measurement}

The density of the glass microspheres was determined using a MicromeriticsAccuPyc 1330 helium pycnometer (Norcross, GA, USA). The equipment was calibrated using a standard calibration ball $\left(3.18551 \mathrm{~cm}^{3}\right)$ with error of $\pm 0.03 \%$. Glass microsphere samples, with an average weight of approximately $1 \mathrm{~g}$, were used for the density measurements, and the analysis was performed in triplicate. The bulk or tap density of the microspheres were also carried out using the following Equation 1.

$$
\operatorname{Density}(\rho)=\frac{\operatorname{Weight}(W)}{\operatorname{Volume}(V)} \quad \text { Equation } 1
$$

\section{Porosity and BET surface area analysis}

The porosity of the porous microspheres was evaluated via mercury intrusion porosimetry (Micromeritics Autopore IV 9500). A 5 cc powder penetrometer (Micromeritics) with 1 cc intrusion volume was used for all of the glass formulations investigated. Before running the samples, an empty penetrometer test was also carried out as a blank. The porosity of the microspheres was also calculated using the following Equation 2.

$$
\text { Porosity }=\left(1-\frac{\text { Bulk density }}{\text { True density }}\right) \times 100 \quad \text { Equation } 2
$$

Surface area measurements were carried out using a Micromeritics ASAP 2420 utilising Krypton $(\mathrm{Kr})$ as an adsorbate. Approximately $0.25 \mathrm{~g}$ of sample were carefully weighed into a sample tube with a sealed frit. Samples were degassed at $250^{\circ} \mathrm{C}$ for $15 \mathrm{hr}$ under vacuum to remove moisture and other adsorbed gases. $\mathrm{Kr}$ Isotherms were carried out from 0.07 to 0.25 relative pressure $(\mathrm{P} / \mathrm{Po})$ at $-196{ }^{\circ} \mathrm{C}$ in liquid nitrogen. Specific BET surfaces were calculated from the isotherms 
using the BET model in the above relative pressure range using Microactive V3.0 software package (Micromeritics Instrument Corporation).

\section{Thermal Analysis}

Thermal properties of the glass samples (including bulk glass (BG), SGMS and PGMS) were characterised using a simultaneous thermal analysis instrument (SDT, TA Instruments SDT Q600, USA) to obtain glass transition $\left(T_{g}\right)$, onset of crystallisation $\left(T_{x}\right)$, crystallisation peak $\left(T_{c}\right)$ and melting peak $\left(T_{m}\right)$ temperatures. Approximately $20 \mathrm{mg}$ of glass samples were placed into a platinum pan and heated from room temperature to $1100^{\circ} \mathrm{C}$ at $20^{\circ} \mathrm{C} \mathrm{min}-1$ heating rate. An empty pan was also run to determine the baseline, which was then subtracted from the thermal traces using TA Universal Analysis 2000 software.

\section{Degradation, $\mathrm{pH}$ and ion release studies}

To evaluate the kinetics of material degradation rate, ion release and $\mathrm{pH}$ solution changes, $1 \%$ $\mathrm{w} / \mathrm{v}$ of microspheres were immersed in milli-Q water and incubated at $37^{\circ} \mathrm{C}$. Assessments were performed on day $1,3,7,10,14$ and 28 . To determine the degradation rate, the microspheres were dried at $50^{\circ} \mathrm{C}$ overnight and then weighted using a precision scale (Sartorius CP 225D). The percentage of mass loss was calculated according to the following Equation 3:

$$
\text { Mass Loss }(\%)=\frac{M_{0}-M_{t}}{M_{0}} \quad \text { Equation } 3
$$

Where $M_{o}$ is the initial mass $(\mathrm{mg})$ of microspheres and $M_{t}$ is the mass obtained at each time point. The $\mathrm{pH}$ of the solution was measured using a microprocessor $\mathrm{pH}$ meter (Mettler Toledo, Switzerland) previously calibrated using standard $\mathrm{pH}$ buffer solutions of $\mathrm{pH} 4.0, \mathrm{pH} 7.0$ and $\mathrm{pH}$ 10.0 (Fisher Scientific, UK). The concentration of sodium, calcium, magnesium, phosphorous and 
titanium ions was determined by inductively coupled plasma mass spectrometry (ICP-MS, Thermo-Fisher iCAP-Q model).

The concentration of sodium, calcium, magnesium, phosphorous and titanium ions released was also determined for sterilised porous microspheres incubated in DMEM $(1 \% \mathrm{w} / \mathrm{v})$ at $37{ }^{\circ} \mathrm{C}$ in order to investigate the amounts of ions cells were exposed to in culture. Conditioned DMEM medium was collected at day 1, 2, 6, 10, 12 and 14; DMEM was refreshed every 48 hours for the entire study in order to mimic closely the medium refreshment regimen performed in cell culture studies.

\section{In vitro bioactivity studies}

In vitro bioactivity was tested in simulated body fluid (SBF) at day 7, 14, 21 and 28. The SBF solution was prepared following the standard procedure of BS ISO 23317:2014. The SBF solution was kept at $5^{\circ} \mathrm{C}$ for $48 \mathrm{~h}$ prior to use and Bioglass $45 \mathrm{~S} 5$ (irregular shaped particles) was also tested to confirm the apatite forming ability of the SBF solution. $75 \mathrm{mg}$ of microspheres (solid and porous) were immersed in $50 \mathrm{ml} \mathrm{SBF}$ solution at $37^{\circ} \mathrm{C}$ in a polyethylene vial and agitated at 120 rpm. At each time point, the microspheres were filtered and washed with deionised water and then dried overnight at $50^{\circ} \mathrm{C}$ in an oven. XRD, SEM and EDX analysis were utilised to explore the structural, morphological and compositional changes, respectively. The $\mathrm{pH}$ values of the SBF solution were also measured at each time point.

\section{Microspheres sterilisation and preparation of conditioned media for cell study}

Sterilization of microspheres was performed throughout two washes of 15 minutes with ethanol $70 \%$ followed by complete evaporation at room temperature in sterile conditions. For the preparation of conditioned medium containing microsphere ion extracts, $100 \mathrm{mg} / \mathrm{ml}$ of sterile 
microspheres were incubated in standard cell culture medium (SM) (low glucose DMEM supplemented with $10 \%$ foetal calf serum, $1 \%$ penicillin and streptomycin, $1 \%$ L-Glutamine, $1 \%$ of non-essential aminoacid, Thermofisher, UK) at $37^{\circ} \mathrm{C}$ and $5 \% \mathrm{CO}_{2}$. The same concentration of non-degradable commercial solid soda-lime (SL) microspheres (Hodge Clemco Ltd, UK) were also included and tested as a negative control non-degradable glass. The conditioned media containing microsphere ion extracts were collected and replaced with equal volume of fresh medium every 48 hours for 21 days. Before being administrated to the cells, the solutions were filtered throughout $0.8 \mu \mathrm{m}$ syringe filters to remove any debris or precipitate.

\section{Cell culture and differentiation}

For the indirect culture model with microsphere-conditioned media, immortalised GFP-labelled human bone marrow-derived mesenchymal stem cells (hMSCs) $[19,30]$ were seeded at a density of 4,000 cells $/ \mathrm{cm}^{2}$ in $300 \mu \mathrm{l}$ of standard cell culture medium in 48 -well plates. The plates were previously coated with Reduced Growth Factor Matrigel (Gibco ${ }^{\mathrm{TM}}$, Thermofisher, UK) diluted 1:500 in cold DMEM. 48 hours after seeding, cells were washed with PBS and $300 \mu$ of conditioned media were added. Cells cultured with either unconditioned standard medium (SM), or osteogenic medium (OM) (standard cell culture medium supplemented with $0.1 \mathrm{mM}$ dexamethasone, $10 \mathrm{mM} \beta$-glycerophosphate, and $50 \mu \mathrm{M}$ ascorbic acid (Sigma-Aldrich, UK) ) were used as controls. All media were refreshed every 48 hours. Two independent biological replicates were performed with 5 experimental replicates for each condition.

For the direct seeding model, hMSCs were seeded on $10 \mathrm{mg}$ of sterile microspheres at density of 10,000 cells $/ \mathrm{cm}^{2}$ into low-adherent 48 -well plate previously coated with $200 \mu \mathrm{l}$ of $1 \% \mathrm{w} / \mathrm{v}$ solution of poly(2-hydroxyethyl methacrylate) (poly-HEMA) (Sigma-Aldrich, UK) and Ethanol $95 \%$ 
[31]. Cells were cultured at $37^{\circ} \mathrm{C}$ and $5 \% \mathrm{CO}_{2}$ in $300 \mu \mathrm{l}$ of standard medium refreshed every 48 hours. Cells seeded on SL and cultured with SM or OM were included as negative and positive control, respectively. Two independent experiments were performed with 3 experimental replicates for each condition (Figure S1).

\section{Metabolic activity assay}

Presto Blue cell viability assay (Invitrogen ${ }^{\mathrm{TM}}$, Thermofisher, UK) was used to analyse the cell metabolic activity in both indirect and direct cultures at day 2. A working solution was prepared by supplementing the standard medium with $10 \%$ of Presto Blue reagent and $300 \mu$ were dispensed per well. After 40 minutes of incubation at $37{ }^{\circ} \mathrm{C}$ and $5 \% \mathrm{CO}_{2}, 250 \mu \mathrm{l}$ of the solution were transferred to a clear bottom 96-well plate; fluorescence was measured at $560 \mathrm{~nm}$ and 590 $\mathrm{nm}$ as excitation and emission wavelengths using a Infinite 200 microplate reader (Tecan, $\mathrm{CH}$ ).

\section{DNA content assay}

Pico-Green ${ }^{\circledR}$ dsDNA quantitation kit (Invitrogen ${ }^{\mathrm{TM}}$, Thermofisher, UK) was used to measure DNA amounts in cultures at day 2, 12 and 21 . For the direct culture samples, the cell-microsphere aggregates were first mechanically broken using a scalpel. For both indirect and direct cultures, $100 \mu \mathrm{l}$ of sterile distilled water were added to each sample followed by three freezing-thawing cycles. Then, $95 \mu$ l of sample suspension were transferred to a clear bottom 96-well plate. A DNA standard curve was prepared using the lambda virus DNA provided. Measurement of fluorescence was performed in an Infinite 200 microplate reader (Tecan, CH) at $480 \mathrm{~nm}$ and 520 $\mathrm{nm}$ as excitation and emission wavelengths, respectively. 


\section{Alkaline phosphatase activity assay}

Alkaline phosphatase (ALP) activity was assayed at day 12 of culture for both types of experiments. A solution containing $1 \mathrm{mg} / \mathrm{ml}$ p-nitrophenyl phosphate and $0.2 \mathrm{M}$ TRIS buffer (SIGMAFAST, Sigma-Aldrich, UK) was prepared according to the manufacturer's instructions. Cells in 48-well plates were washed twice with PBS and $300 \mu$ l of assay solution were added to each well. For the direct culture samples, cell-microsphere aggregates were mechanically disaggregated. ALP activity was monitored at $405 \mathrm{~nm}$ using an Infinite 200 microplate reader (Tecan, $\mathrm{CH}$ ) pre-set at $37^{\circ} \mathrm{C}$.

\section{Alizarin Red staining}

Alizarin Red S staining was performed at day 21 of indirect culture experiments. Cells were fixed for 10 minutes with $4 \%$ paraformaldehyde at $4{ }^{\circ} \mathrm{C}$, followed by two PBS washes. Before staining, two washes with deionized water were performed followed by the addition of $200 \mu \mathrm{l}$ of $1 \% \mathrm{w} / \mathrm{v}$ Alizarin Red S solution (Sigma-Aldrich, UK). After 15 minutes, samples were extensively washed with deionized water before imaging. For stain quantitation, samples were incubated with 200 $\mu$ of destaining solution (20\% methanol, $10 \%$ acetic acid in deionized water) during 15-20 minutes before measuring the absorbance at $405 \mathrm{~nm}$.

\section{Sample imaging}

Bright-field and fluorescence images of living cells were taken using an EclipseT2 Nikon microscope coupled with a D3300 Nikon camera.

For Environmental Scanning Electron Microscopy, fixed cells were washed twice with distilled water and imaged using a FEI Quanta 650 (Thermo Fisher Scientific) [19]. 


\section{Statistical analysis}

Results of the biological study represent two independent repeats presented as mean \pm standard error of the mean (SEM). One-way ANOVA with Tukey's multiple comparison post hoc test was used. A $95 \%$ confidence level was considered significant. Statistical analysis was performed with the GraphPad PRISM 7.01 software package.

\section{RESULTS}

The composition of the phosphate glass formulations investigated and used to prepare microspheres are presented in Table 1, along with their respective glass codes used and oxide contents obtained, which were all within $1.5 \mathrm{~mol} \%$ of their expected values.

Table 1: Comparison and glass codes used for the three different phosphate glass formulations selected for microsphere preparation and characterisation.

\begin{tabular}{|l|l|l|l|l|l|l|}
\hline \multirow{2}{*}{ Glass code } & & $\begin{array}{l}\mathrm{P}_{2} \mathrm{O}_{5} \\
(\mathrm{~mol} \%)\end{array}$ & $\begin{array}{l}\mathrm{MgO} \\
(\mathrm{mol} \%)\end{array}$ & $\begin{array}{l}\mathrm{CaO} \\
(\mathrm{mol} \%)\end{array}$ & $\begin{array}{l}\mathrm{Na}_{2} \mathrm{O} \\
(\mathrm{mol} \%)\end{array}$ & $\begin{array}{l}\mathrm{TiO}_{2} \\
(\mathrm{~mol} \%)\end{array}$ \\
\hline \multirow{2}{*}{ M24T0 } & Expected & 40 & 24 & 16 & 20 & \multirow{2}{*}{ N.A. } \\
\cline { 2 - 7 } & Obtained & $39.9 \pm 0.1$ & $23.5 \pm 1.7$ & $16.3 \pm 1.6$ & $20.3 \pm 0.6$ & \\
\hline \multirow{2}{*}{ M8T0 } & Expected & 40 & 8 & 32 & 20 & \multirow{2}{*}{ N.A. } \\
\cline { 2 - 7 } & Obtained & $39.9 \pm 0.1$ & $8.3 \pm 0.5$ & $31.4 \pm 0.6$ & $20.5 \pm 0.2$ & \\
\hline \multirow{2}{*}{ M2T1 } & Expected & 40 & 2 & 38 & 19 & 1 \\
\cline { 2 - 7 } & Obtained & $40 \pm 0.1$ & $2.5 \pm 0.1$ & $36.9 \pm 0.2$ & $19.7 \pm 0.1$ & $0.9 \pm 0.1$ \\
\hline
\end{tabular}




\section{Surface morphology, XRD and EDX analysis of microspheres}

Figure 1 shows that both solid and porous glass microspheres were successfully prepared via the flame spheroidisation processing route [19]. Figures $\mathbf{1 A}$ and $\mathbf{B}$ confirm the microsphere morphologies obtained of both the solid and porous phosphate-based glass microspheres via SEM analysis.

In order to examine the internal structure of the porous phosphate glass microspheres, they were embedded in a cold setting epoxy resin, ground and polished using SiC paper and diamond cloth, to a depth of a few microns to obtain microsphere cross-sections. Figure $1 \mathrm{C}$ shows the crosssections of the porous phosphate glass microspheres obtained via SEM, which showed not only a large variation of internal pore sizes (ranging from meso to macropores), but also showed that the pores were all interconnected.

XRD traces for the solid and porous glass microspheres are presented in Figure 1D (i) and (ii) respectively, where a single broad peak between $20^{\circ}$ and $40^{\circ}(2 \theta)$ was observed for solid glass microspheres of each composition. The absence of any sharp crystalline peaks for SGMS suggested that the glass microspheres retained their amorphous nature. However, small sharp peaks were observed for the porous glass microspheres from each of the compositions explored. 
A

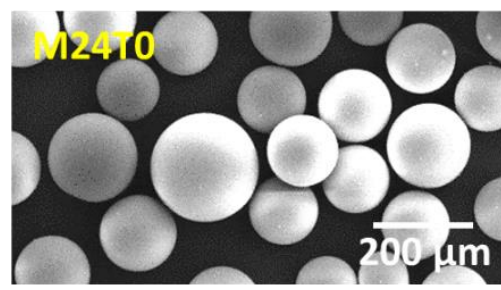

B

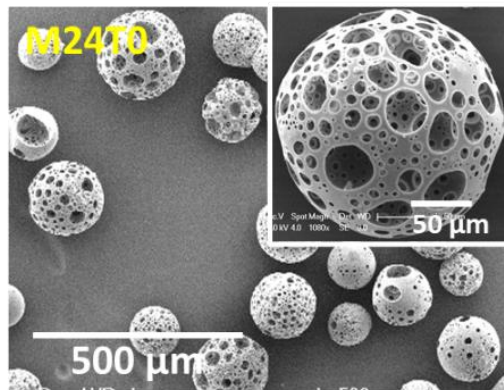

C

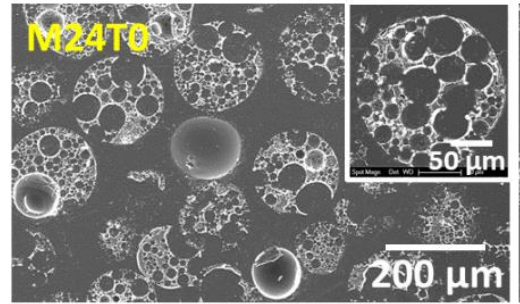

i) SGMS

D

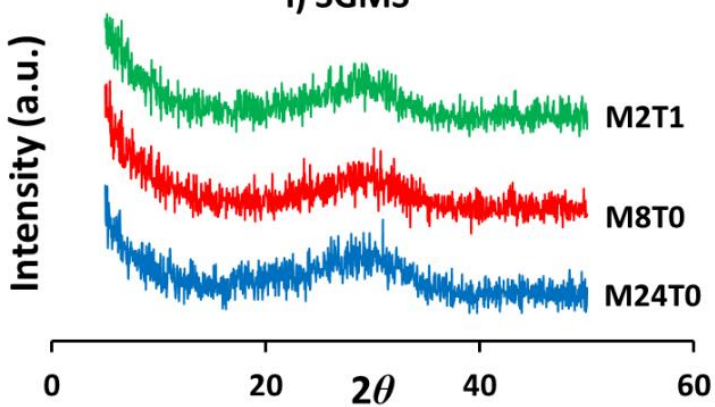

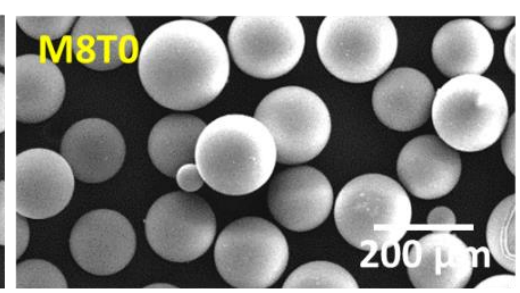
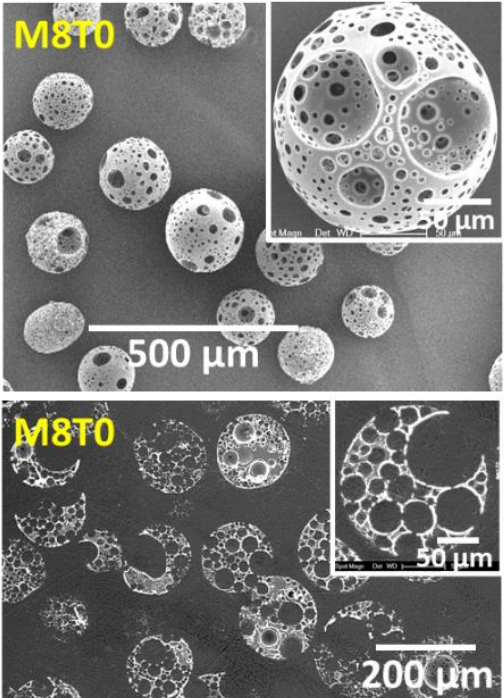

$200 \% \mathrm{~m}$
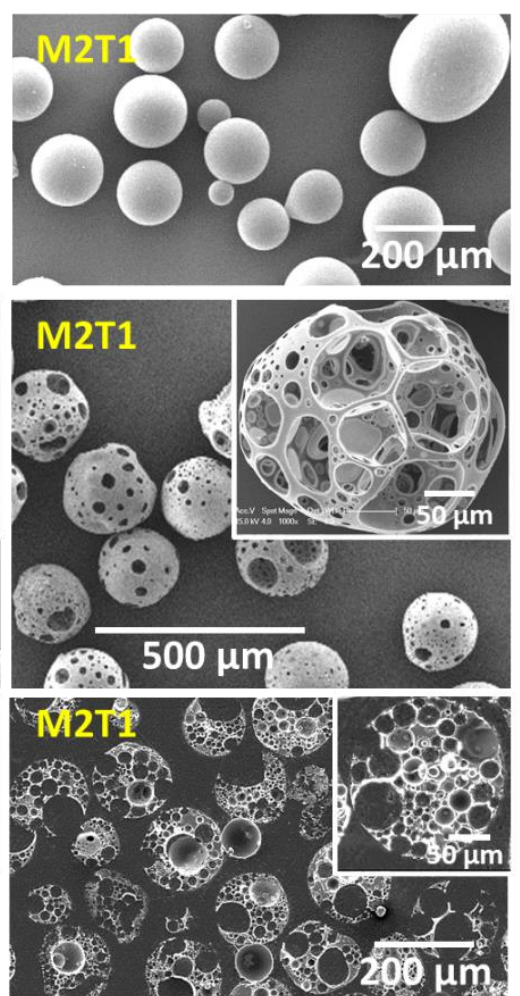

ii) PGMS

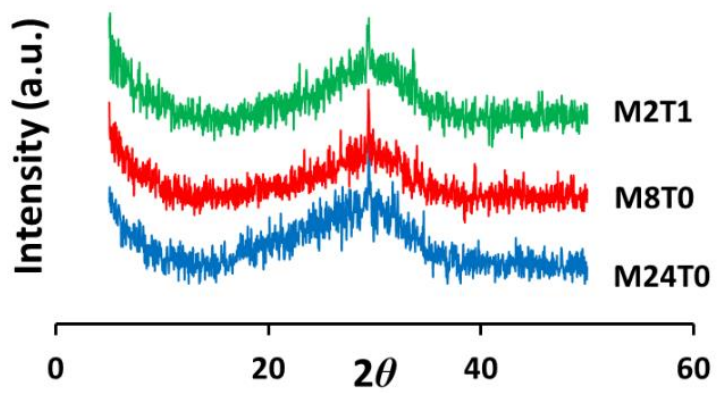

Figure 1: SEM images of (A) SGMS and (B) PGMS, and (C) cross-sections of porous microspheres and (D) X-ray diffraction patterns for SGMS and PGMS of M24TO, M8TO and M2T1 glass formulations investigated.

Figure S2 highlights the chemical compositions obtained from EDX analysis of the initial bulk glass material produced (BG), solid microspheres (SGMS) and porous microspheres (PGMS) for M24T0, M8T0 and M2T1. As seen from Figure S2, no significant variation of chemical composition between BG and SGMS was observed for all three glass formulations. However, significantly 
higher $\mathrm{CaO}$ content and lower $\mathrm{P}_{2} \mathrm{O}_{5}$ content was observed for the PGMS in comparison to the SGMS. For example, around 5 mol\% lower $\mathrm{P}_{2} \mathrm{O}_{5}$ and 7 mol\% higher $\mathrm{CaO}$ content was observed for PGMS of M2T1 as compared to the BG and SGMS of the same formulation.

\section{Density, Porosity and Surface area}

Table 2 shows the density (measured via He pycnometer and tap density), porosity and surface area of the solid and porous microspheres for M24T0, M8T0 and M2T1. As seen from Table 2, the density and tap density reduced significantly. However, the theoretical porosity calculated increased 2 fold for the PGMS for all of the glass compositions when compared to SGMS. For example, density and tap density of SGMS were found to be around 2.6 and $1.6 \mathrm{~g} / \mathrm{cm}^{3}$, respectively. Whereas, density and tap density for the porous microspheres was found to be around 2.5 and $0.6 \mathrm{~g} / \mathrm{cm}^{3}$, respectively. In addition, the theoretical calculated porosity (interparticle packing porosity for SGMS, inter-particle packing porosity and actual porosity for PGMS) of SGMS and PGMS were found to be $\sim 35$ and $\sim 75 \%$, respectively. The theoretically calculated porosity values (\%) (using Equation 2) for PGMS were found to be very similar to the experimentally data obtained via mercury porosimetry (see Table 2).

All of the glass formulations within the size range $(125-200 \mu \mathrm{m})$ were expected to exhibit similar surface area for the SGMS. Surface area for SGMS (M24T0) were found to be $0.0231 \mathrm{~m}^{2} / \mathrm{g}$. Whereas, PGMS of same glass formulation (M24T0) revealed a $94 \%$ increase in surface area compared to SGMS in the same size range. PGMS of M8T0 and M2T1 glass formulations showed similar surface areas to PGMS of M24T0 and interestingly the values obtained were under $1 \mathrm{~m}^{2} / \mathrm{g}$ (see Table 2). 
Table 2: Density, porosity and surface area of solid and porous microspheres of three different phosphate-based glasses investigated.

\begin{tabular}{|c|c|c|c|c|c|c|c|c|c|}
\hline $\begin{array}{c}\text { Glass } \\
\text { formulations }\end{array}$ & \multicolumn{3}{|c|}{ SGMS } & \multicolumn{5}{c|}{ PGMS } \\
\cline { 2 - 10 } & $\begin{array}{c}\text { Density (He } \\
\text { Pycnomete } \\
\mathrm{r})\left(\mathrm{g} / \mathrm{cm}^{3}\right)\end{array}$ & $\begin{array}{c}\text { Tap density } \\
(\mathrm{Tap}) \\
\left(\mathrm{g} / \mathrm{cm}^{3}\right)\end{array}$ & $\begin{array}{c}\text { Inter- } \\
\text { particle } \\
\text { packing } \\
\text { porosity } \\
(\%)\end{array}$ & $\begin{array}{c}\text { Surface } \\
\text { area } \\
\left(\mathrm{m}^{2} / \mathrm{g}\right)\end{array}$ & $\begin{array}{c}\text { Density (He } \\
\text { Pycnometer) } \\
\left(\mathrm{g} / \mathrm{cm}^{3}\right)\end{array}$ & $\begin{array}{c}\text { Tap } \\
\text { density } \\
(\mathrm{Tap}) \\
\left(\mathrm{g} / \mathrm{cm}^{3}\right)\end{array}$ & $\begin{array}{c}\text { Porosity } \\
(\mathrm{Hg} \\
\text { porosity) } \\
(\%) \\
\text { Open }\end{array}$ & $\begin{array}{c}\text { Porosity } \\
(\text { Calculat } \\
\text { ed) } \\
(\%)\end{array}$ & $\begin{array}{c}\text { Surface } \\
\text { area } \\
\left(\mathrm{m}^{2} / \mathrm{g}\right)\end{array}$ \\
\hline M24T0 & $\begin{array}{c}2.650 \pm \\
0.002\end{array}$ & $1.63 \pm 0.02$ & $36 \pm 3$ & 0.0231 & $2.516 \pm 0.002$ & $0.59 \pm 0.02$ & $76 \pm 5$ & $77 \pm 2$ & 0.4187 \\
\hline M8T0 & $\begin{array}{c}2.596 \pm \\
0.004\end{array}$ & $1.58 \pm 0.06$ & $37 \pm 3$ & - & $2.475 \pm 0.008$ & $0.56 \pm 0.03$ & $74 \pm 4$ & $77 \pm 3$ & 0.3794 \\
\hline M2T1 & $2.627 \pm$ \\
0.006 & $1.69 \pm 0.02$ & $35 \pm 4$ & - & $2.182 \pm 0.02$ & $0.74 \pm 0.02$ & $69 \pm 5$ & $69 \pm 2$ & 0.4345 \\
\hline
\end{tabular}

The pore diameters measured using mercury porosimetry against the log differential pore volume are presented in Figure $\mathbf{S 3}$. It should be noted that mercury porosimetry determines the largest entrance to a space as a pore which is not always the actual "pore size" [32]. M24T0 PGMS showed multimodal pore size distribution with the first prominent peak showing a modal value of c.a. $55 \mu \mathrm{m}$, second peak at c.a. $30 \mu \mathrm{m}$, third peak at c.a. $5 \mu \mathrm{m}$ and the fourth peak at c.a. $2 \mu \mathrm{m}$. Moreover, the analysis revealed pore sized features at submicron down to nanoscale porosity levels as shown in ESI Figure 3. A trimodal behaviour was observed for M8T0 and M2T1 PGMS with the first two prominent peaks displaying a modal pore diameter of c.a. $45 \mu \mathrm{m}$ and c.a. 21 $\mu \mathrm{m}$ and the modal pore diameter for the third peak appeared at c.a. $3 \mu \mathrm{m}$.

\section{Thermal properties and degradation studies}

Figure $2 \mathrm{~A}$ shows the thermal traces of $\mathrm{BG}, \mathrm{SGMS}$ and $\mathrm{PGMS}$ where the corresponding glass transition $\left(T_{g}\right)$, crystallisation onset $\left(T_{x}\right)$, crystallisation peak $\left(T_{c}\right)$ and melting $\left(T_{m}\right)$ temperature 
have been labelled. The thermal data such as $T_{g}, T_{x}, T_{c}$ and $T_{m}$ for the three different morphologies (i.e. bulk glass, solid and porous glass microspheres) are also presented in Table S1. No significant changes were observed for $\mathrm{T}_{\mathrm{g}}$ and initial melting temperature among $\mathrm{BG}, \mathrm{SGMS}$ and PGMS of the same glass formulation (see Table S1). However, no melting peak was observed for M2T1 PGMS. On the other hand, SGMS showed higher $T_{x}$ and $T_{c}$ in comparison to their respective BG formulation. Whereas, PGMS showed lower values for $T_{x}$ and $T_{c}$ compared to $B G$. For example, $17^{\circ} \mathrm{C}$ higher $\mathrm{T}_{\mathrm{x}}$ and $22^{\circ} \mathrm{C}$ higher $\mathrm{T}_{\mathrm{c}}$ value were observed for SGMS of M24T0 than for BG. On the other hand, $46{ }^{\circ} \mathrm{C}$ lower in $\mathrm{T}_{x}$ and $25^{\circ} \mathrm{C}$ lower in $\mathrm{T}_{\mathrm{c}}$ value were observed for PGMS of M24T0 as compared to BG.

A

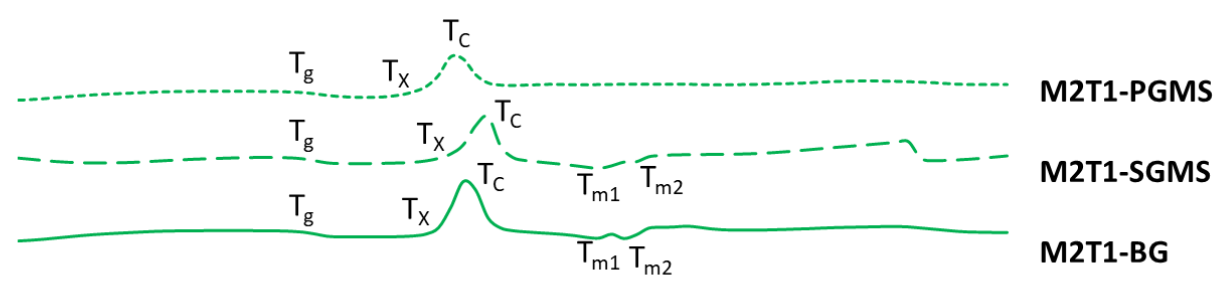

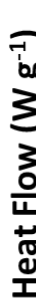
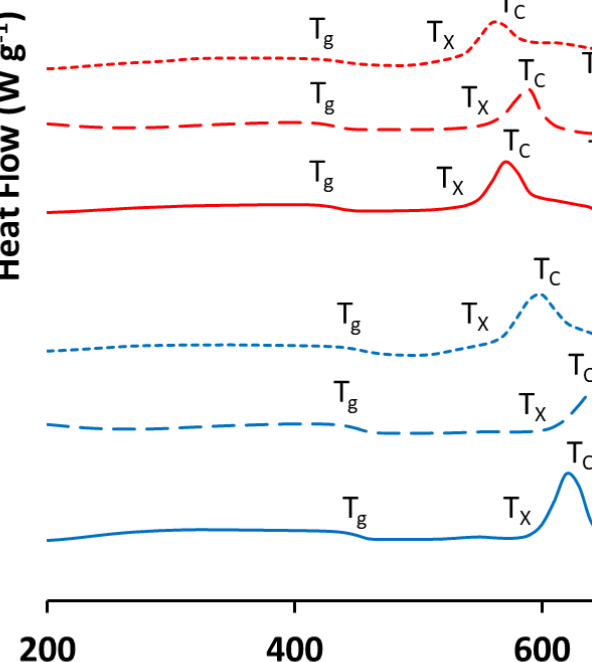

200

400
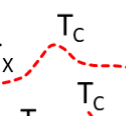

$\mathrm{T}_{\mathrm{x}} / \mathrm{T}_{\mathrm{C}}$
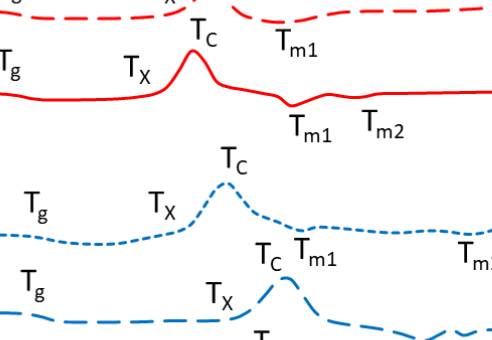

$\mathrm{T}_{\mathrm{m} 2}$

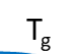

$\mathrm{T}_{\mathrm{g}}$
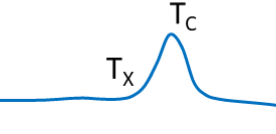

M24T0-SGMS

M24T0-BG

M8T0-SGMS

M8T0-BG

M24T0-PGMS
$T_{m 1} T_{m 2}$

600

800

1000

Temperature $\left({ }^{\circ} \mathrm{C}\right)$

Figure 2: A) DSC curves for the starting glass particles, solid and porous glass microspheres of M24TO, M8TO and M2T1. Bulk glass (BG) depicted as solid line, solid glass microspheres (SGMS) shown as dashed line and the porous glass microspheres (PGMS) are shown as the dotted line. 

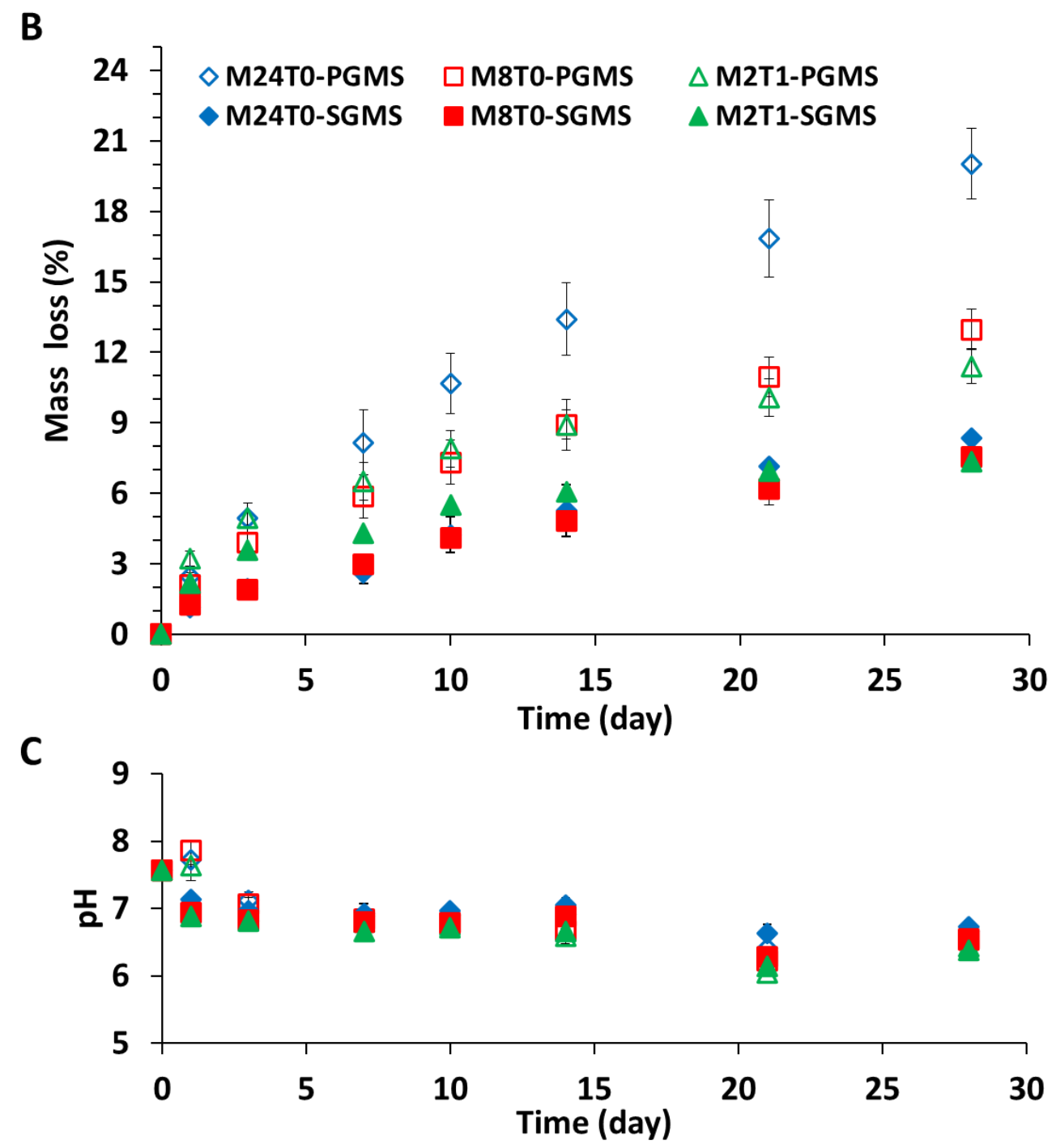

Figure 2: B) Mass loss (\%) and C) $p H$ change as a function of immersion time (day) for the solid and porous glass microspheres of M24TO, M8TO and M2T1 in milli-Q water at $37^{\circ} \mathrm{C}$ over 28 days. Solid symbols represent SGMS, whilst the open symbols represent the porous counterparts.

The degradation profiles of the glass microspheres degraded in milli-Q water presented in Figure 2B showed an increase in mass loss with increasing degradation time for all glass formulations (SGMS and PGMS). As expected, the PGMS showed higher mass loss compared to SGMS of the 
same respective glass composition. For example, PGMS of M24T0 showed around 2.5 times higher mass loss at day-28 in comparison to SGMS (see Figure 2B). The mass loss \% of PGMS were found to be 20, 13 and $11.4 \%$ for M24T0, M8T0 and M2T1, respectively after 28 days of immersion in milli-Q water. Whereas, SGMS showed only $8.3 \%$ for both M24T0 and M2T1 and $7.5 \%$ mass loss for M8T0 in milli-Q water at day 28.

The $\mathrm{pH}$ for the medium (milli-Q water) with PGMS increased from $\sim 7.5$ to $\sim 7.7$ at day 1 for all of the glass compositions, then gradually decreased to $\sim 6.2$ with increasing degradation time up to day-21 (Figure 2C). On the other hand, the $\mathrm{pH}$ values for the solution with SGMS gradually decreased to same value ( 6.2 ) with increasing degradation time up to day-21. After 28 days, the $\mathrm{pH}$ values were found to be 6.5 for both SGMS and PGMS.

Figures S4A and B show representative SEM images of SGMS and PGMS after 28 days of immersion in milli-Q water, respectively. Higher degradation was observed for higher magnesium containing microspheres (both SGMS and PGMS; i.e M24T0) compared to lower magnesium containing microspheres (i.e. M8T0 and M2T1). PGMS seemed to degrade uniformly whereas, some of SGMS degraded more compared to other SGMS.

\section{Ion release profiles}

The cumulative ion release profiles of the glass formulations tested in milli-Q water appeared to follow a linear relationship with time (see Figures 3 A-E). The release rates of each ion for SGMS and PGMS are shown in the inset of Figures 3 A-E. All of the ion release rates for PGMS were higher compared to their respective SGMS.

From Figures 3 A, C and D, the highest $\mathrm{Na}^{+}(197.1 \mathrm{ppm}), \mathrm{Mg}^{2+}(98.9 \mathrm{ppm})$ and $\mathrm{P}(472.9 \mathrm{ppm})$ ion release were observed for PGMS of M24T0 whereas the lowest $\mathrm{Na}^{+}(152.9 \mathrm{ppm}), \mathrm{Mg}^{2+}(18.1 \mathrm{ppm})$ 
and P (255.9 ppm) ion release were observed for PGMS of M2T1 at day 28 among the PGMS. On the other hand, $\mathrm{Ca}^{2+}$ ion release was found to be similar for all of the PGMS (highest 115 ppm for M8T0 PGMS and lowest 108 ppm for M2T1 PGMS) at day 28 (see Figure 3 B).

The ion release profiles for SGMS followed similar trends to that of PGMS with significantly lower ion release. For example, $45 \%$ higher $\mathrm{Na}^{+}, 33 \%$ higher $\mathrm{Ca}^{2+}, 41 \%$ higher $\mathrm{Mg}^{2+}$ and $53 \%$ higher $\mathrm{P}$ ion release were observed for the PGMS of M24T0 as compared to the SGMS (see Figures 3 AD). 

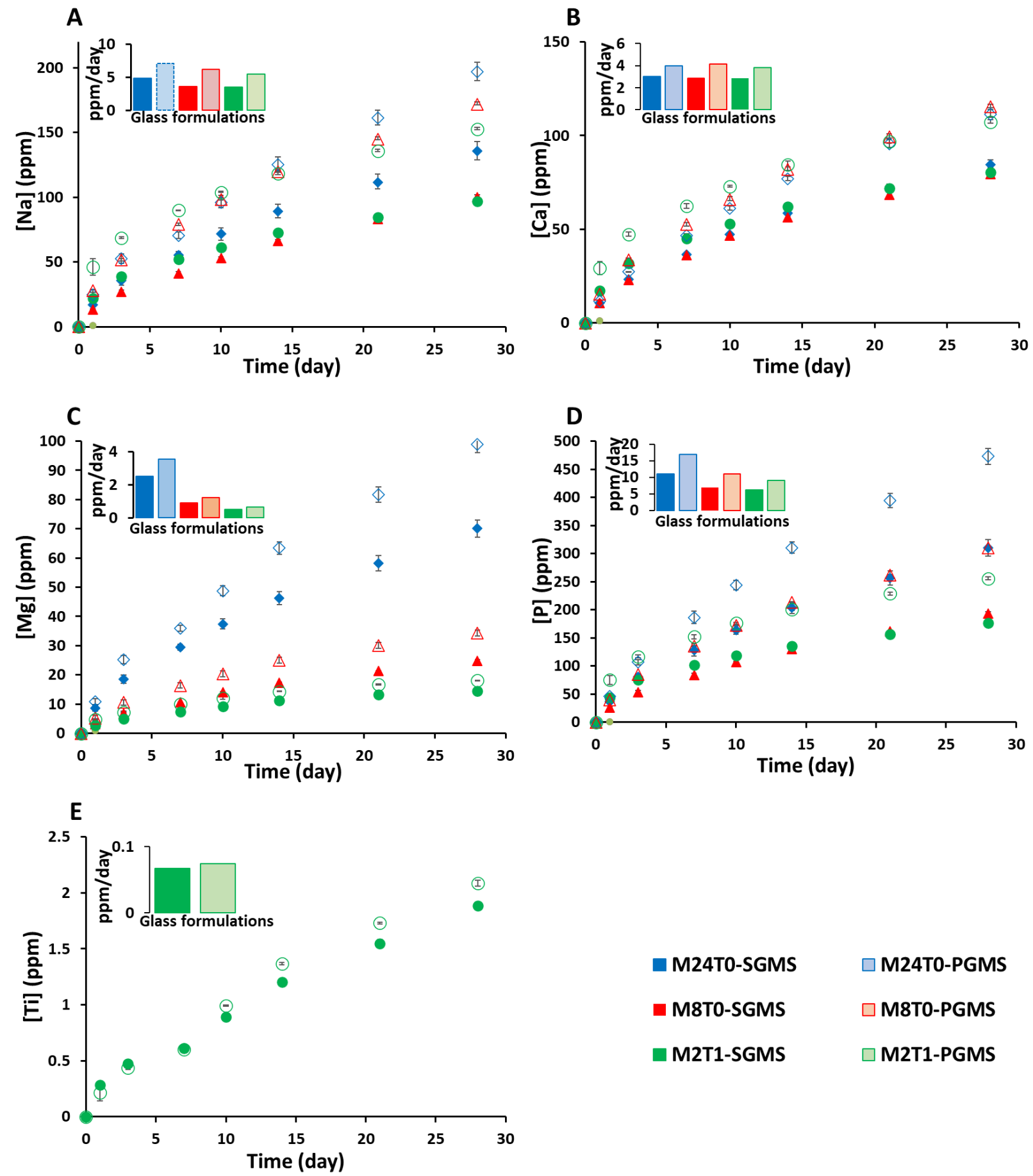

Figure 3: Cumulative ion release profile of $A)[\mathrm{Na}], B)[\mathrm{Ca}, \mathrm{C})[\mathrm{Mg}], \mathrm{D})[\mathrm{P}]$ and E) $[\mathrm{Ti}]$ measured via ICP-MS for SGMS and PGMS of phosphate glasses investigated in milli-Q water during 28 days of immersion period. (Error bars are also included in the data above). The Inset on each graph shows the release rates of each element for the glass formulations investigated. 
In order to more accurately reflect the ion release profiles that the cells may experience within a cell culture environment, $\mathrm{Na}, \mathrm{Ca}, \mathrm{Mg}, \mathrm{P}$ (total) and $\mathrm{Ti}$ ions released in DMEM media were also investigated for PGMS of M24T0, M8T0 and M2T1 and SGMS of soda-lime (SL - used as a control) via ICP-MS and presented in Figure S5 (ion release data are also shown in Table S2). The medium was refreshed every 48 hours to perform the cell culture study and values were recorded at day 1, 2, 6, 10, 12 and 14. Table S3 summarises the statistical differences of ion release observed between the formulations considered. As shown, similar amounts of sodium were released by all formulations over the 14 days of study, whilst for calcium the only significant difference detected was between samples of M8T0 and SL at day 12. Moreover, significantly higher amounts of magnesium were released by M24T0 in comparison to all other conditions during the study. The amount of phosphorous released was significantly higher in M24T0 and M8T0 in comparison to M2T1, SL and DMEM from day 6 . A burst release of titanium was observed for M2T1 at day 1 but not at later time points (see Figure S5).

\section{In Vitro SBF study}

In order to explore the bioactivity of these PBG microspheres, microspheres were immersed in SBF up to 28 days. The corresponding XRD traces of both the solid and porous microspheres after 28 days of immersion in SBF are shown in Figures $4 A$ and $B$. The absence of crystalline peaks suggests that no apatite formation occurred during the bioactivity study. However, the apatiteforming ability of the prepared SBF solution was confirmed using bioactive 4555 bioglass (irregular-shaped particles) as control, where crystalline apatite peaks were seen after 7 days of immersion in SBF (see Figure S6). 
SEM images of the SGMS and PGMS after 28 days of immersion in SBF are shown in Figures 4C-

E. A few highly degraded SGMS (shown in yellow circles; see Figure 4C-E) were observed whereas, the PGMS remained intact up to day 28. Precipitate deposits were clearly observed at higher magnification on the surface of degraded solid glass microspheres (shown in yellow circles; see Figure 4C-E). A rough surface appearance of the M24T0 porous glass microspheres was also clearly observed at higher magnification (see Figure 4C) with precipitation deposits seen inside the PGMS of M8T0 (see Figure 4D at higher magnification). 


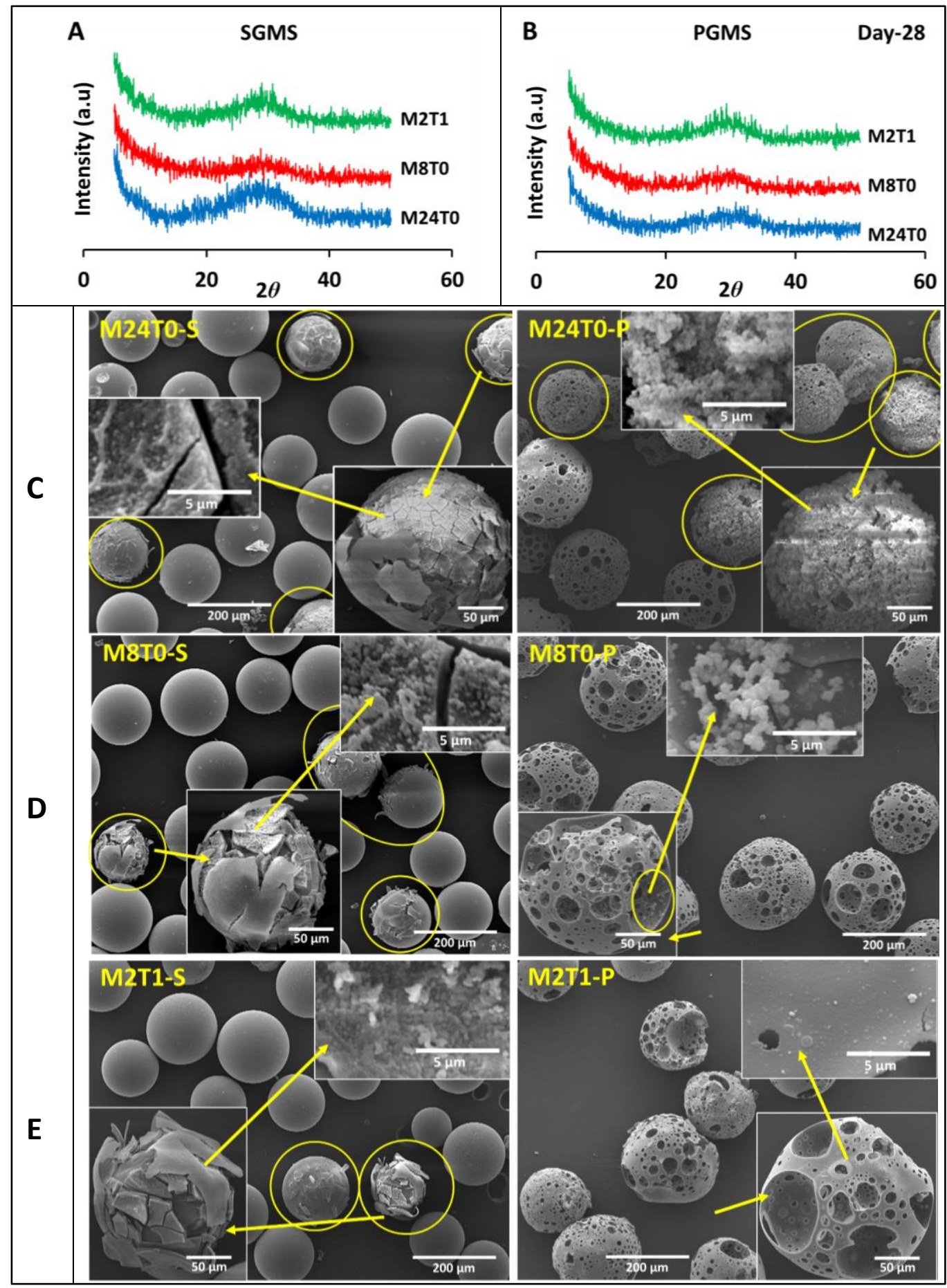

Figure 4: X-ray diffraction pattern for A) SGMS and B) PGMS, and SEM images of SGMS and PGMS of C) M24TO, D) M8TO and E) M2T1 glasses after 28 days of immersion in SBF. The inset SEM images show the changes in surface morphology at higher magnification. Highly degraded SGMS and deposition of CaP on microspheres shown in yellow circle. 
Table 3 highlights the Ca/P atomic ratio of the SGMS and PGMS for the glass formulations investigated via EDX before and after 28 days of immersion in SBF. No significant changes of the $\mathrm{Ca} / \mathrm{P}$ ratio were observed for the SGMS between day-0 and day-28 in SBF. However, significantly higher $\mathrm{Ca} / \mathrm{P}$ ratios were obtained for some SGMS (highly degraded microspheres, presented in red circles in Figure 4C) after 28 days of immersion in SBF. For example, the Ca/P ratio increased from 0.2 to 0.7 for M24T0, 0.41 to 0.78 for M8T0 and 0.48 to 0.87 for M2T1. On the other hand, $\mathrm{Ca} / \mathrm{P}$ ratio for $\mathrm{PGMS}$ of all glass formulations investigated increased after 28 days of immersion in SBF. Significant changes of Ca/P were found for PGMS of M24T0, where Ca/P ratio increased from 0.27 to 0.75 after 28 days immersion in SBF.

Table 3: Ca/P (atomic ratio) of SGMS and PGMS for three glasses before and after 28 days of immersion in SBF.

\begin{tabular}{|c|c|c|c|c|c|c|}
\hline \multirow{2}{*}{ Time point } & \multicolumn{3}{|c|}{ SGMS } & \multicolumn{3}{c|}{ PGMS } \\
\cline { 2 - 7 } & M24T0 & M8T0 & M2T1 & M24T0 & M8T0 & M2T1 \\
\hline Day 0 & $0.2 \pm 0.01$ & $0.41 \pm 0.03$ & $0.48 \pm 0.02$ & $0.27 \pm 0.04$ & $0.5 \pm 0.05$ & $0.62 \pm 0.07$ \\
\hline & \multicolumn{5}{|c|}{ Overall average EDX values } \\
\cline { 2 - 7 } Day 28 & $0.3 \pm 0.02$ & $0.47 \pm 0.03$ & $0.55 \pm 0.02$ & $0.75 \pm 0.04$ & $0.82 \pm 0.06$ & $0.92 \pm 0.05$ \\
\cline { 2 - 7 } & \multicolumn{5}{|c|}{ Average EDX values for specific microspheres } \\
\cline { 2 - 7 } & $0.7 \pm 0.06$ & $0.78 \pm 0.08$ & $0.87 \pm 0.07$ & $0.77 \pm 0.05$ & $0.83 \pm 0.04$ & $0.93 \pm 0.06$ \\
\hline
\end{tabular}

In addition, the SBF media post immersion maintained a relatively neutral $\mathrm{pH}$ value (at around 7.4) over the period of study for both solid and porous glass microspheres (see Figure S7). 


\section{Cellular response to PBG microspheres through indirect cell exposure}

An indirect culture system was established by exposing hMSCs to medium conditioned with microspheres, in order to evaluate the biological response to the composition and degradation products released by the different PGMS over time. Ion extracts of SL microspheres were included as negative control.

\section{Effect of conditioned media on cell metabolic activity and proliferation}

The analysis of metabolic activity performed at day 2 of indirect culture revealed no differences in cell response between medium conditioned with the M24T0 and M8T0 formulations, the standard medium (SM) and the soda-lime microspheres which were included as negative controls (SL). However, a significantly lower cell response was observed for the formulation M2T1 in comparison to all other culture conditions (vs SM, M24T0, M8T0 $p<0.0001 ;$ vs SL $p<0.05$ ) (Figure 5A). Brightfield images of treated cells at day 2 confirmed the formation of homogenous cell monolayers in the presence of medium conditioned with M24T0 and M8T0, and the control of SM and SL whereas samples exposed to M2T1 conditioned medium showed sparse cells with elongated processes and the presence of debris around and on top of the cells (Figure 5B).

DNA quantification was performed at day 2, 12 and 21 in order to evaluate the effect of the conditioned media on cell growth (Figure $\mathbf{5 C}$ ). The results indicated an increase of DNA amount over time for all conditions and no significant differences between the formulations and the controls (SM and SL) was observed. 
A

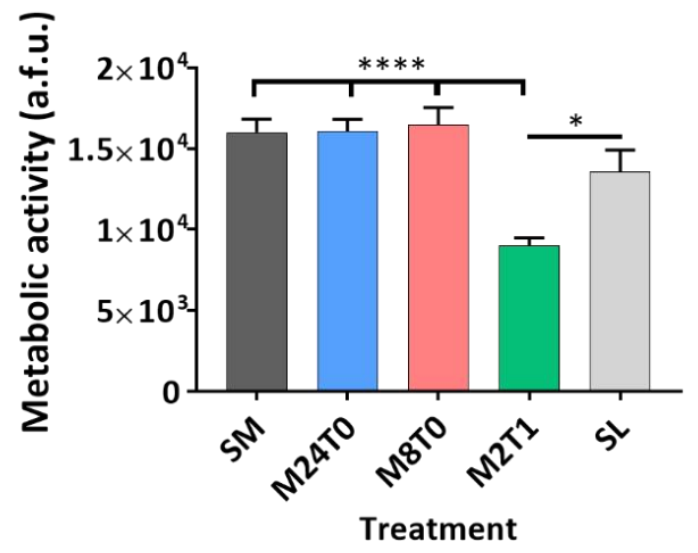

C

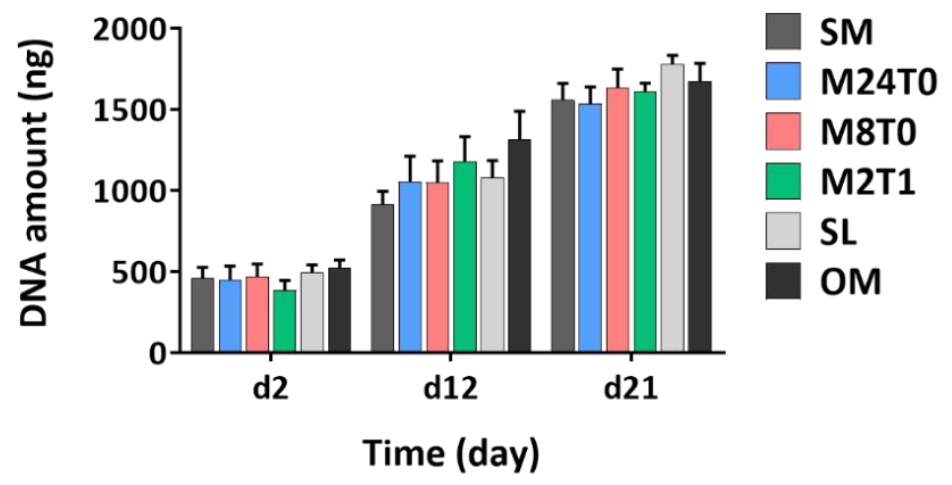

B
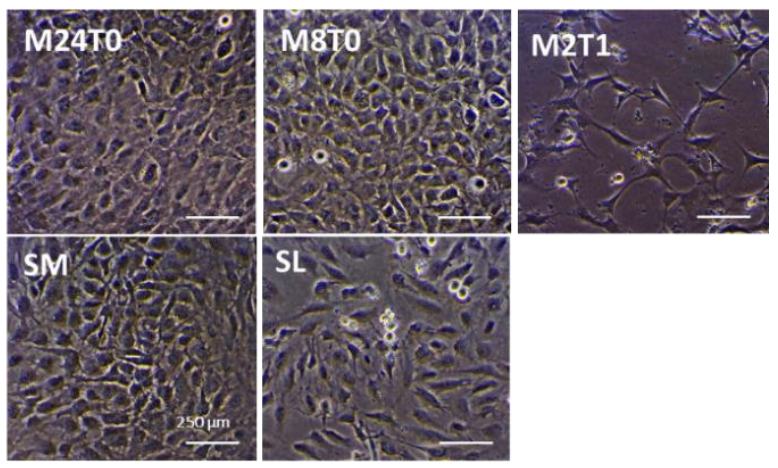

Figure 5: Evaluation of cell growth in cultures exposed to PGMS-conditioned medium. A) Cell metabolic activity assayed at day 2; B) Cell appearance at day 2 of culture; C) Quantification of DNA amount over the entire experiment (day 2, day 12, day 21). Scale bar: $250 \mu m . * * * * p<$ $0.0001 ; *<0.05$

\section{Effect of microsphere ion extracts on osteogenic differentiation}

Alkaline phosphatase activity measured at day 12 showed significantly higher values for cells exposed to medium conditioned from M24T0 and M8T0 formulations $(p<0.05)$ in comparison to the SM control (Figure 6A).

At day 21, Alizarin Red staining used to mark mineralized extracellular matrix (Figure 6B) showed significantly higher values for medium conditioned with the formulation M24T0 in comparison 
to the SM and SL controls $(p<0.05)$. The Alizarin red-positive response induced by M24T0conditioned medium was variable across the biological replicates performed, resulting in a large error in the measurement (Figure 6B and figure S8).

A

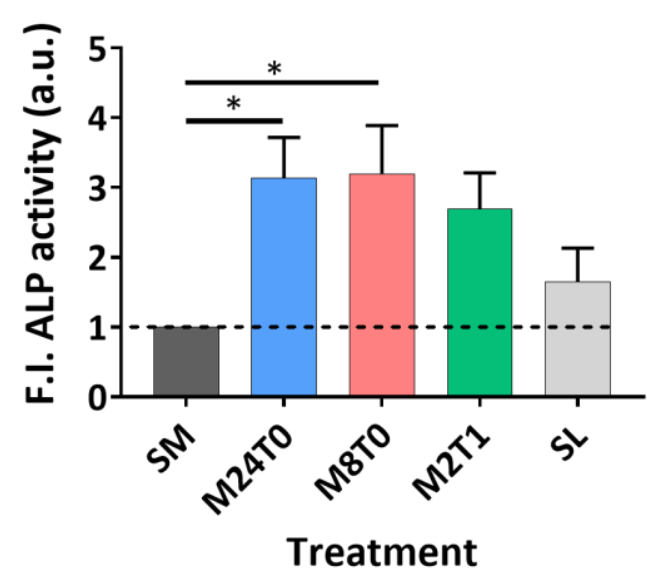

B

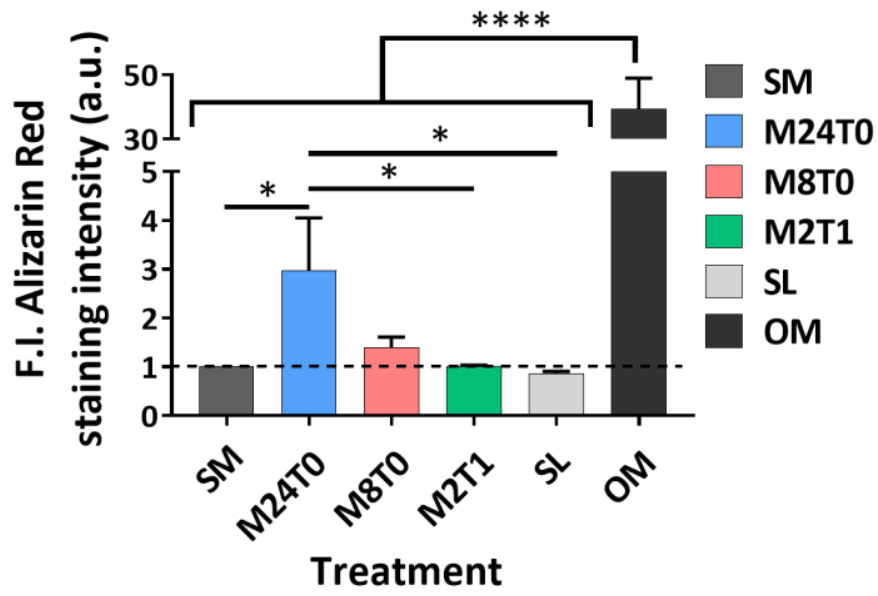

Figure 6: Evaluation of osteogenic differentiation through analysis of (A) ALP activity performed at day 12 and (B) Alizarin Red staining at day 21 in cultures exposed to PGMS-conditioned medium. ${ }^{* * * *} p<0.0001 ; * p<0.05$.

\section{Assessment of PBG microspheres biological potential through direct culture}

Direct seeding of human MSCs on the microspheres was performed in order to assess the cellular response to direct contact with the different formulations and evaluate their potential as carriers for cell culture and delivery.

\section{Evaluation of cell metabolic activity and DNA semi-quantitation}

The cell response to physical contact with microspheres was evaluated from day 2 by analysis of metabolic activity, which showed a significantly higher response in cells cultured on M24T0 and M8T0 in comparison to the SL negative control (vs SL-SM: $p<0.001$; vs M8T0: $p<0.05$; vs M2T1: 
$p<0.01$ ) (Figure 7A). Results from the DNA semi-quantitation at day 2, day 12 and day 21 however showed significantly higher amounts for M2T1 in comparison to SL and M24T0 at day 2 $(p<0.01)$, although these differences levelled out by day 21 when no differences were observed (Figure 7B). Live cell imaging (Figure 7C) showed that cells already adhered onto the microspheres at day 2, bridging between several microspheres. Over time, cell growth was observed with the formation of spherical aggregates by day 12 , showing several microspheres surrounded by a cell mass as previously described [19].

A

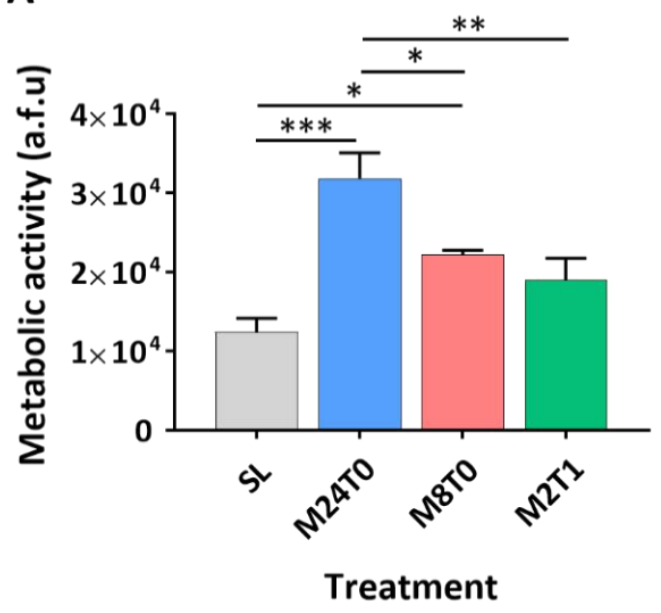

B

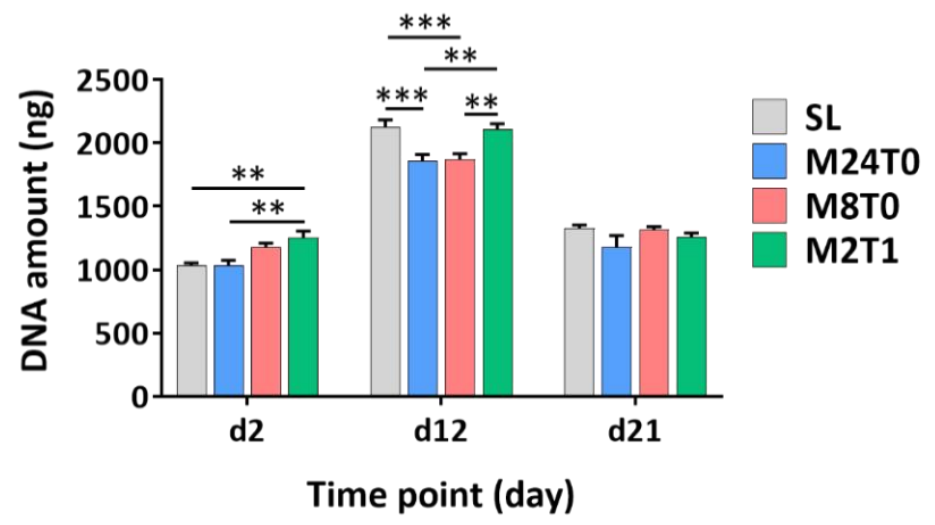

C

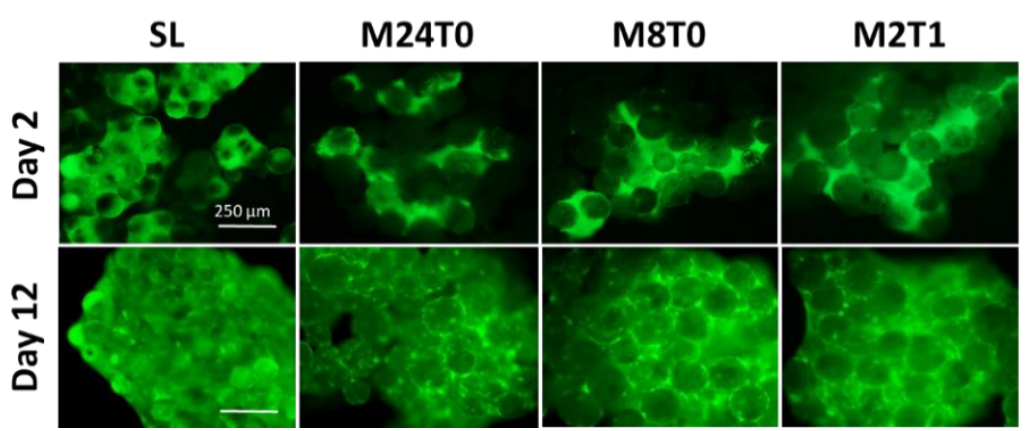

Figure 7: Evaluation of cell metabolic activity and growth in direct cultures. A) Metabolic activity of cells cultured on microspheres for 48h. B) Semi-quantitation of DNA content performed at day 2, day 12 and day 21.C) Live-cell imaging performed at day 2 and day 12. Scale bar $=250 \mu m$. *** $p<0.001 ; * *<0.01 ; *<0.05$. 


\section{Alkaline Phosphatase activity measured in cells cultured onto microspheres}

Alkaline Phosphatase activity was evaluated after 12 days of culture on the PBG microspheres, while the activity of cells measured at day 0 was included as baseline (Figure $\mathbf{8 A}$ ). By day 12 , no significant differences were detected between cells cultured onto the different materials, although all showed a significant increase in comparison to day 0 . To confirm the ability of cells to undergo osteogenic differentiation, cells cultured on soda-lime microspheres in the presence of osteogenic medium (SL-OM) were also included and showed a significantly higher response in comparison to the other culture conditions $(p<0.0001)$.

\section{ESEM imaging of cell-seeded microspheres}

Cell-microsphere aggregates images were captured through ESEM in order to evaluate the morphological response to the different formulations (Figure 8B). ESEM images at day 21 showed marked differences in the appearance and conformation of the extracellular matrix (ECM) embedding the microspheres from the PBG formulations compared to both controls. For cells seeded on SL, the ECM looked smooth and homogeneous, largely surrounding the microspheres with a thin layer of cellular material detectable on the microspheres surface. In the positive controls (SL-OM), some nodule-like structures were visible around and attached to the microspheres (see red arrows in Figure 8B). However, on the PBG samples, the cells formed a thick matrix spreading on and around the material surface bridging together several microspheres. Nodule-like structures resembling those observed in the SL-OM positive control were also visible in the three groups (see red arrows). Over the 21 days in culture, the cells were also seen to invade and colonise inside the pores, adhering to the inner wall (see yellow arrowheads in Figure 8B) and spreading in a 3D conformation. 


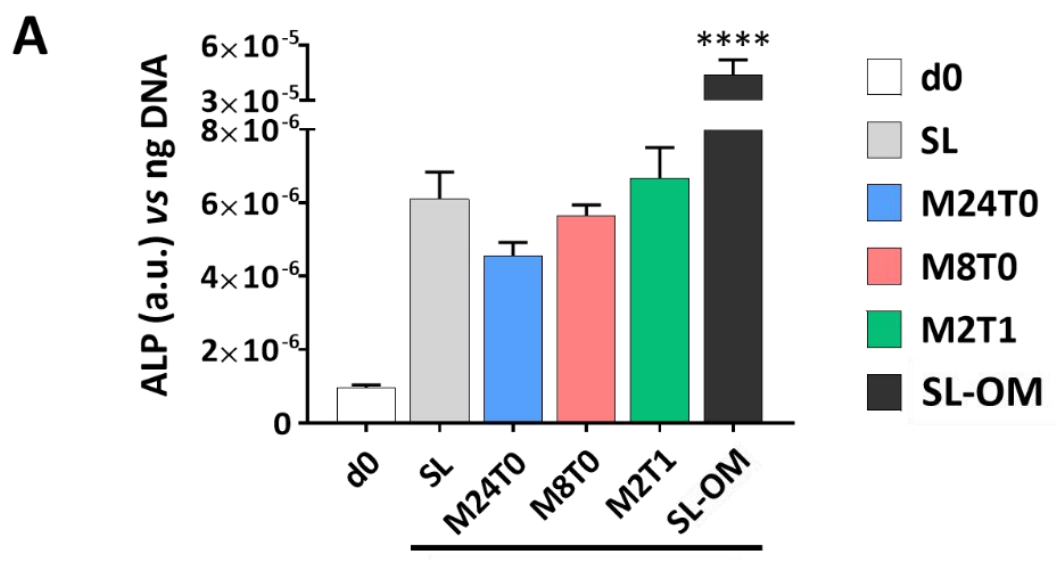

Day 12

B
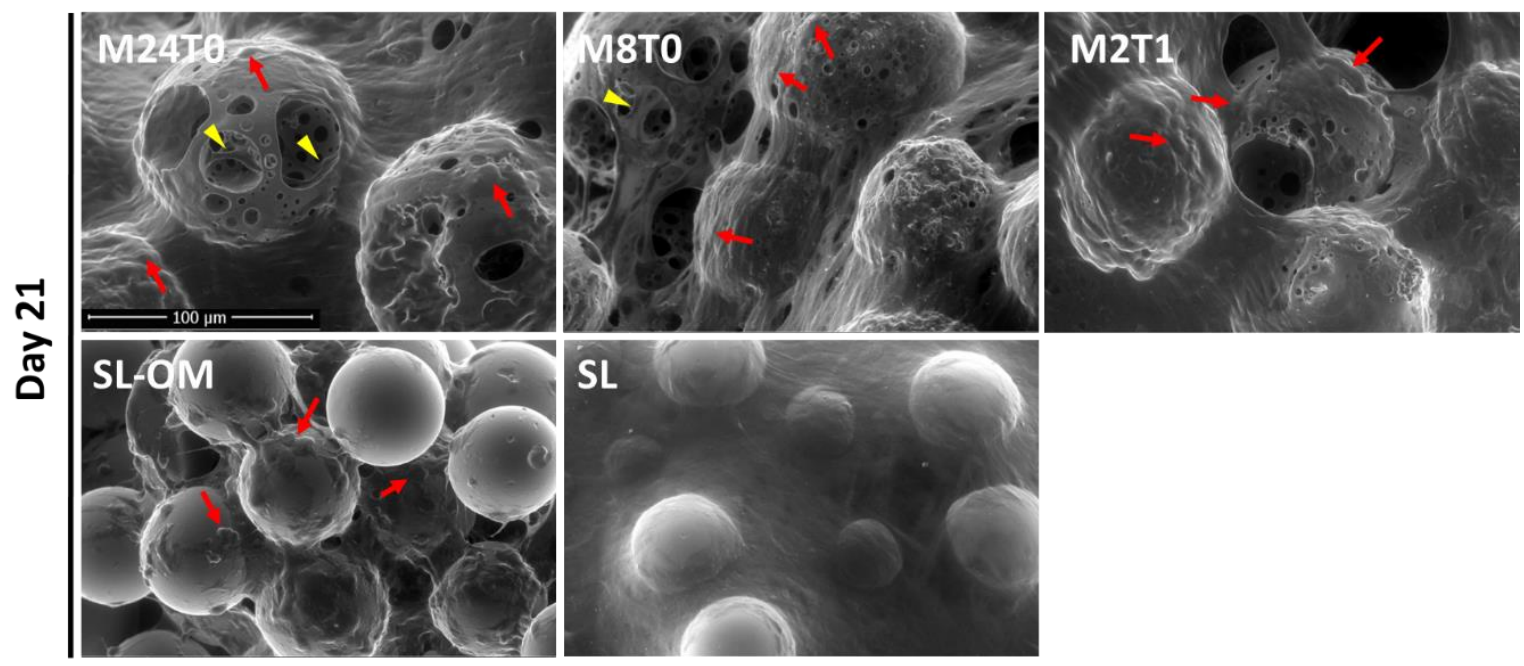

Figure 8: Evaluation of ALP activity and ESEM imaging in direct cultures. A) ALP was evaluated at day 12 in living cells upon mechanical disaggregation of the cell-microsphere aggregates. ${ }^{* * * *} p$ $<0.0001$; B) ESEM imaging was performed at day 21 for the three PGMS formulations, and sodalime microspheres cultured with standard medium (SL) or osteogenic medium (SL-OM). Red arrows point at nodule-like structures identified across formulations and yellow arrowheads point at cells which have migrated inside the pores of the PGMS. 


\section{DISCUSSION}

This paper reports on the production (via flame spheroidisation process) and characterisation of solid and porous phosphate-based glass microspheres of three formulations (M24T0, M8T0 and M2T1) [29] explored for bone tissue engineering applications. To confirm the microspheres' ability to support cell growth and osteogenic potential, biological and physicochemical properties of the microspheres were evaluated.

Glass particles were successfully transformed into microspheres due to surface tension forces during the cooling stage as the molten glass particles were ejected from the flame [33]. To manufacture porous microspheres various factors need to be considered, such as chemical and physical interaction of the porogen with the glass formulations, glass viscosity, along with both components (porogen and glass particles) being delivered within a suitable thermal processing window and within a sufficient timeframe [19]. To achieve a high yield of porous microspheres, the materials delivered need to melt reaching a viscosity suitable to entrap the gas released as the porogen decomposes within the molten globules but also to enable the gas to escape before the particles cool and solidify. Previous studies from our research group also showed that both porogen quantity and particle size could affect the final pore sizes (and hence surface area) [19]. Post spheroidisation, it was seen that the SGMS retained their amorphous nature. However, for the PGMS a small single peak in XRD analysis corresponding to $\mathrm{CaCO}_{3}$ was observed for each composition, which was attributed to the use of the carbonate-based porogen. The use of porogen in this process also increased the Ca content, which consequently decreased the $\mathrm{P}$ content for the PGMS (as observed from EDX analysis). Whereas, no significant variation in composition between the starting BG and SGMS was observed. 
The thermal properties of PGMS, especially onset of crystallisation and crystallisation peaks, shifted to lower temperatures in comparison to their BG and SGMS counterparts of the same composition. This was attributed to the higher surface area: volume ratio [34] of the PGMS and due to potential remnants of the porogen used or incorporation of $\mathrm{CaO}$ from the porogen decomposition stage (which also correlated with the EDX analysis).

A similar shifting of the crystallisation peak to higher temperatures with increasing particle size, and consequently decreasing surface area:volume ratio, was observed by Al-noaman et al. for silicate glasses [34]. This was in line with the previously reported shift of the crystallisation peaks [35] (from $587^{\circ} \mathrm{C}$ to $643^{\circ} \mathrm{C}$ ) with increasing PBG particle size ranges (from 45-100 $\mu \mathrm{m}$ to 350-500 $\mu \mathrm{m})$, further confirming the influence of particle sizes on thermal properties. The onset of crystallisation and crystallisation peaks for the SGMS shifted to slightly higher temperatures in comparison to the irregular shaped BG particles of the same composition. This shift could also be attributed to differences in surface area due to i) the initial size distribution of the experimental particle size range $(125-200 \mu \mathrm{m})$ and ii) possible agglomerating molten particles during the SGMS production process, leading to larger particle sizes.

The surface area obtained via BET confirmed the higher surface area profiles for PGMS in comparison to SGMS. The cross-sectional SEM images of the porous microspheres revealed their internal porosity, which clearly showed interconnected pores for all the glass formulations investigated. Mercury porosimetry revealed 2 times higher porosity ( 75\%) for PGMS compared to SGMS ( 36\%), taking into account that the inter-particulate gaps for both samples contributed to the measurement of the overall porosity. BET analysis showed a significant ( $94 \%)$ increase of surface area for PGMS in comparison to SGMS. The values obtained appeared to be quite low 
(i.e. $<1 \mathrm{~m}^{2} \mathrm{~g}^{-1}$ ). However, these were mainly attributed to the highly porous shell-like structures of the porous microspheres formed along with their fully open interconnected porosity features. The introduction of porosity also led to an increase in mass loss (approximately 2.5 times higher) and ion release rates (for $\mathrm{Na}, \mathrm{Ca}, \mathrm{Mg}, \mathrm{P}$ and $\mathrm{Ti}$ ) in comparison to the SGMS, which was expected due to their increased surface area. No significant variation in mass loss \% was observed among the SGMS of PBG glasses investigated. Whereas, the SGMS showed significantly higher mass loss $\%$ in comparison to the previously reported bulk glass discs of the same composition [29] due to higher surface area for SGMS. However, the mass loss \% profiles observed for the PGMS was opposite to that previously reported for the glass discs [29]. This reverse trend in PGMS mass loss as compared to bulk glass discs could be attributed to i) differences in surface area between the PGMS formulations tested, and ii) to structural changes that may have occurred during the processing of PGMS (i.e. addition of $\mathrm{CaO}$ during the porogen decomposition stage). The post flame spheroidisation changes to the chemical composition observed showed an increase of $\mathrm{CaO}$ by 7 mol\% for PGMS of M2T1 which would of have enhanced their durability. Ahmed et al. studied the effect of $\mathrm{Ca}$ content on dissolution of PBG in $\mathrm{P}_{2} \mathrm{O}_{5}-\mathrm{CaO}-\mathrm{Na}_{2} \mathrm{O}$ glass system and reported that the degradation of PBGs decreased with increasing Ca content in place of Na due to increase in the cross-linking between the phosphates chains [3]. Moreover, in our previous study [29], the glass formulation with $\mathrm{CaO}$ content above 32 mol\% (glass series $40 \mathrm{P}_{2} \mathrm{O}_{5}-(24-$ x) $\left.\mathrm{MgO}-(16+x) \mathrm{CaO}-20 \mathrm{Na}_{2} \mathrm{O}\right)$ showed a strong tendency towards crystallisation. Further analysis (via XRD) on crushed PGMS in comparison to the intact PGMS revealed that apart from the initial $\mathrm{CaCO}_{3}$ peaks which were observed for the M8T1 and M2T1 PGMS, additional crystalline peaks of alpha-calcium pyrophosphate $\left(\alpha-\mathrm{Ca}_{2} \mathrm{P}_{2} \mathrm{O}_{7}\right)$ were also present (see Figure $\mathbf{S 9}$ ). 
Slight increases in $\mathrm{pH}$ values were observed at day-1 for PGMS, which then gradually decreased at later time-points, reaching a slightly acidic $\mathrm{pH}$ around 6.5 at day-28. These were possibly due to the slightly higher anions (total P ion) released than cations.

The cations and anions released correlated well with the mass loss profiles observed. Controlling ion release profiles from phosphate-based glasses is one of the key advantages of these materials and this control would potentially be very useful not only for bone repair and regeneration, but also for other biomedical applications. For example, $\mathrm{Ca}^{2+}$ ions are known to help stimulate proliferation and differentiation of osteoblasts as well as extracellular matrix mineralisation [36], whilst $\mathrm{Mg}^{2+}$ ions have been shown to be very useful for new bone formation [37]. In addition, $\mathrm{PO}_{4}{ }^{3-}$ ions are required for calcium phosphate crystal deposition [38] and extracellular matrix mineralisation, whilst $\mathrm{Na}^{+}$ions are mainly found in extracellular fluid [39]. Therefore, imparting control over the ion release profiles of these materials is thus an important parameter that could be further controlled via their unique morphology.

When investigating in vitro bioactivity, although 28-day incubation in SBF did not lead to the detection of apatite on the surface of either solid and porous microspheres, the values of $\mathrm{Ca} / \mathrm{P}$ obtained (0.68-0.87) for SGMS and (0.75-0.92) for PGMS were within the range suggested for amorphous calcium phosphate (ACP) $(0.67$ to 1.5$)[40,41]$, a precursor phase towards formation of hydroxyapatite [42]. It is noted that the real $\mathrm{Ca} / \mathrm{P}$ ratios might be higher than the observed values, due to the difficulties of performing EDX analysis and accurately determining the composition of a thin layer on the surface of the microspheres. Also, the presence of epoxy resin used for embedding the microspheres could represent an additional technical issue in performing accurate measurements. 
Based on the physico-chemical properties of the formulations presented in this study, the ability of the porous microspheres to support cell growth and osteogenic commitment and provide a 3dimensional environment for cell growth was analysed using human mesenchymal progenitors. The addition of material ions extracts was investigated to predict the effect of material degradation products on cells response, which is a key parameter for the success of tissue regeneration approaches in vivo $[43,44]$. The results obtained in long-term culture (21 days) confirmed that microspheres of the three formulations were cytocompatible.

Although an early cytotoxic effect was indicated by the morphological evaluation and by the significant decrease of metabolic activity when cells were exposed to M2T1 extracts, possibly due to the presence of precipitate debris observed at day-2 $[9,45]$, this was transitory and cultures recovered over longer culture periods.

The osteogenic differentiation response to porous microspheres extracts, in the absence of osteogenic factor supplementation, was also analysed. Medium conditioned with the formulation M24T0 induced the highest osteogenic response, with Alizarin Red-positive bonelike nodules visible in one out of two biological replicates. This variability in the osteogenic response may have been due to the fact that independent batches of cells, although at similar passage number, were used to carry out the experiments.

The other formulations M8T0 and M2T1 showed limited effect on the activity of the early marker ALP and did not trigger any detectable mineral deposition, suggesting a limited effect on early osteogenic commitment. This result suggested that the M24T0 formulation released ions at a more favourable profile for cell stimulation, and thus warrants further analysis. However, these in vitro observations differ from a study which reported that between 70 and $400 \mathrm{ppm}$ of $\mathrm{Ca}^{2+}$ 
ions were required to significantly promote osteocalcin expression and matrix mineralization with no alterations to cell viability at up to $300 \mathrm{ppm} \mathrm{[46].} \mathrm{In} \mathrm{another} \mathrm{study,} \mathrm{the} \mathrm{number} \mathrm{of} \mathrm{cells}$ in monolayer culture decreased when exposed to $\mathrm{Ca}^{2+}$ concentrations higher than $240 \mathrm{ppm}$, while proliferation increased for cells cultured in a collagen gel soaked in a solution containing $800 \mathrm{ppm}$ of $\mathrm{Ca}^{2+}$ [47]. Regarding the phosphate content, concentrations higher than $240 \mathrm{ppm}$ have been reported to induce proliferation and mineralization $[48,49]$. Similarly, $240 \mathrm{ppm}$ of $\mathrm{Mg}^{2+}$ added to the cell culture as $\mathrm{MgSO}_{4}$ seemed to better stimulate mineralization than lower (120 ppm) or higher concentrations (480-2400 ppm) [50]. These observations contrast with the results obtained here. From the ion release measurements obtained for microspheres tested at $1 \% \mathrm{w} / \mathrm{v}$, it can be estimated that the amount of $\mathrm{Ca}^{2+}$ exposed to the cells during the culture period was between 650 and $950 \mathrm{ppm}$, for the three formulations. The amounts of $\mathrm{P}$ seemed to be between 500 and 1250 ppm whilst the amount of $\mathrm{Mg}^{2+}$ ions were estimated to be between 150 and 440 ppm. It should however be noted that in some previous studies, the effect of each ion has been analysed through their individual administration to cell culture medium $[47,50,51]$, whereas in the present study, cells were exposed to a mix of ions released from the microspheres simultaneously, and therefore a compensation effect between the different ions present in the media could take place.

When cells were seeded directly onto the PGMS however, they were exposed to the effect of both soluble products and physical contact with the material $[43,44]$. Here too, all three formulations promoted cell growth, resulting in the formation of dense cell aggregates as seen at day 12. Interestingly, a general decrease of DNA amount was recorded by day 21 , which could indicate a decrease in cell number at later time-points, or possibly be a technical limitation due 
to the less efficient DNA recovery from very dense cell aggregates present at this stage. ESEM imaging after 21 day in culture revealed the formation of compact and homogeneous aggregates across all formulations, showing a tight and dense matrix, which may have impaired the cell lysis step, limiting the release of DNA during the quantitation assay [52].

Regarding induction of the early osteogenic marker ALP, the trend observed $(\mathrm{M} 24 \mathrm{TO}<\mathrm{M} 8 \mathrm{TO}<$ M2T1), although not statistically significant, contrasted with the results obtained through indirect culture, which suggested M24T0 to provide the most favourable pro-osteogenic environment. This discrepancy may be due to the different culture system used in the indirect and direct culture experiments, and it is plausible that intrinsic materials properties, such as glass surface stability and composition, could have influenced the response of cells directly in contact with the material surface [53]. The trend of ALP activity observed in the direct culture model reflected differences in the dissolution rate of the formulations, with higher values recorded for more stable formulations including the non-degradable control of SL. The stability of the glass surface is known to influence cell response by providing appropriate support for adhesion and growth [54, 55]. In addition to material stability, the presence of titanium in the ion composition of M2T1 glass formulation could have contributed to the increase of ALP activity by promoting activation of the integrin receptor Itg- $\alpha 2 \beta 1$, which has been associated with osteogenic differentiation of cells in vitro $[56,57]$. Glass composition and thus stability also influence tissue response in vivo. A previous study reported that a slower degrading glass formulation doped with $2.5 \mathrm{~mol} \%$ of titanium implanted in an ovine bone defect model delayed tissue maturation, whilst integration with the host tissue was improved when compared to a faster degrading titanium-free glass formulation ( $30 \%$ mass loss over 28 days). In addition, residues of titanium-containing glass were 
still visible in vivo after 13 weeks [5], confirming the significant effect Ti has on promoting stability by significantly decreasing PBG dissolution rates [58].

Based on the in vitro results obtained for the three glass formulations presented here, the M24T0 may be particularly advantageous for the development of a novel phosphate-based glass product for bone tissue repair applications as it provided a favourable balance between sufficient glass stability enabling cell growth and beneficial ion release rates which supported cell growth and osteogenic commitment.

\section{CONCLUSIONS}

This study showed that solid and highly porous phosphate-based glass microspheres in $40 \mathrm{P}_{2} \mathrm{O}_{5}$ (24-x)MgO-(16+x)CaO-(20-y) $\mathrm{Na}_{2} \mathrm{O}-\mathrm{yTiO} \mathrm{TiO}_{2}$ (where $0 \leq x \leq 22$ and $\mathrm{y}=0$ or 1 ) glass system were prepared via a flame spheroidisation process.

PGMS showed fully interconnected porosity (up to $76 \pm 5 \%$ ) with an average pore size of $45-55 \mu \mathrm{m}$ and with surface areas ranging from 0.38 to $0.43 \mathrm{~m}^{2} \mathrm{~g}^{-1}$. Due to increase in porosity and hence surface area, PGMS showed accelerated degradation compared to SGMS over 28 days (i.e. a $20 \%$ mass loss was observed for porous microspheres of M24T0 glass, compared to a $8 \%$ mass loss for the solid non-porous microspheres). The increased ion release profiles of the porous microspheres compared to the non-porous microspheres was attributed to their increased surface area profiles. The in vitro SBF bioactivity study revealed no hydroxyapatite peaks even after 28 days of immersion for both the solid (non-porous) and porous glass microspheres. However, the $\mathrm{Ca} / \mathrm{P}$ ratios (of 0.75 to 0.92 ) were observed for the PGMS of all glass formulations) 
which were within the range suggested for precipitated amorphous calcium phosphate, suggested to be a precursor phase for the formation of HA.

The in vitro cell culture studies confirmed the cytocompatibility of the three formulations investigated, as well as the ability of the porous microspheres to incorporate stem cells within their porous morphology and support osteogenic commitment. The formulations M24T0 seemed to provide the best culture conditions in terms of cell growth and differentiation, warranting further investigation to evaluate the effect it could exert on new bone formation, maturation and organisation.

\section{Electronic supplementary information}

Model for the experimental procedure for indirect and direct cell culture studies (Figure S1); EDX analysis for bulk glass, solid and porous glass microspheres of M24T0, M8T0 and M2T1 (Figure

S2); Pore size distribution (Figure S3); SEM images of solid and porous glass microspheres of M24T0, M8T0 and M2T1 after degradation in mili-Q water (Figure S4); lon release for M24T0, M8T0, M2T1 glass microspheres in DMEM (Figure S5); XRD pattern for $45 \mathrm{~S} 5$ glass particles (as control for in vitro bioactivity study) after 7 days of immersion in SBF (Figure S6); pH change for glass microspheres in SBF (Figure S7); Alizarin red staining ( Semi-quantification and images) (Figure S8); XRD spectra of crushed porous glass microspheres (Figure S9); Thermal properties data (Table S1); Ion release data (in DMEM) (Table S2); Statistical differences of ion release (Table S3) (PDF). 


\section{Conflicts of interest}

There are no conflicts to declare.

\section{ACKNOWLEDGMENT}

This work was supported by the National Institute for Health Research (NIHR) Invention for Innovation (i4i) Challenge Award Programme (II-C3-0714-20001)], and by the University of Nottingham, Faculty of Engineering (the Dean of Engineering Research Scholarship for International Excellence). The authors would also like to acknowledge and thank the Nanoscale and Microscale Research Centre $(\mathrm{nmRC})$ and School of Life Science at the University of Nottingham for use of their instruments and help with analysis.

\section{REFERENCES}

[1] C. Rey, C. Combes, C. Drouet, M.J. Glimcher, Osteoporosis International, 20 (2009) 1013-1021.

[2] M.N. Rahaman, D.E. Day, B.S. Bal, Q. Fu, S.B. Jung, L.F. Bonewald, A.P. Tomsia, Acta biomaterialia, 7 (2011) 2355-2373.

[3] I. Ahmed, M. Lewis, I. Olsen, J. Knowles, Biomaterials, 25 (2004) 491-499.

[4] I. Ahmed, A. Parsons, A. Jones, G. Walker, C. Scotchford, C. Rudd, Journal of biomaterials applications, 24 (2010) 555-575.

[5] J.S. McLaren, L. Macri-Pellizzeri, K.M.Z. Hossain, U. Patel, D.M. Grant, B.E. Scammell, I. Ahmed, V. Sottile, ACS applied materials \& interfaces, 11 (2019) 15436-15446.

[6] E.A. Abou Neel, W. Chrzanowski, G. Georgiou, M.J. Dalby, J.C. Knowles, J Tissue Eng. , 390127 (2010) 1-11. 
[7] E.A. Abou Neel, W. Chrzanowski, S.P. Valappil, L.A. O'Dell, D.M. Pickup, M.E. Smith, R.J.a. Newport, J.C. Knowles, Journal of Non-Crystalline Solids, 355 (2009) 991-1000.

[8] E.A. Abou Neel, J.C. Knowles, J Mater Sci Mater Med. 2008 Jan;19(1):377-86. Epub 2007 Jul 3.

[9] E.A. Abou Neel, T. Mizoguchi, M. Ito, M. Bitar, V. Salih, J.C. Knowles, Biomaterials, 28 (2007) 2967-2977.

[10] I. Ahmed, E.A. Abou Neel, A.J. Parsons, J.C. Knowles, C.D.Rudd, J Biomed Mater Res B Appl Biomater 89 ( 2009 ) 18-27.

[11] T. Alekseeva, J.C. Knowles, R.A.Brown, J Biomater Appl 26 (2012 ) 733-744

[12] M. Bitar, J.C. Knowles, M.P.Lewis , J Biomed Mater Res A 87 (2008 ) 1017-1026.

[13] N.Y. Joo, J.C. Knowles, G.S. Lee, J.W. Kim, H.W. Kim, Y.J. Son, J.K. Hyun, Acta Biomater 8(2012) $1802-1812$.

[14] C. Vitale-Brovarone, J. Lousteau, D. Milanese, S. Raimondo, M. Fornaro, Acta Biomater, 8 (2012) 1125-1136

[15] I. Ahmed, M. Lewis, I. Olsen, J. Knowles, Biomaterials, 25 (2004) 501-507.

[16] A.J. Parsons, I. Ahmed, P. Haque, B. Fitzpatrick, M.I. Niazi, G.S. Walker, C.D. Rudd, Journal of Bionic Engineering, 6 (2009) 318-323.

[17] J.C. Guedes, J.H. Park, N.J. Lakhkar, H.W. Kim, J.C. Knowles, I.B. Wall, J Biomater Appl. 2012 Aug 30.

[18] N.J. Lakhkar, J.H. Park, N.J. Mordan, V. Salih, I.B. Wall, H.W. Kim, S.P. King, J.V. Hanna, R.A. Martin, O. Addison, J.F. Mosselmans, J.C. Knowles, Acta Biomater. 2012 Nov;8(11):4181-90. doi: 10.1016/j.actbio.2012.07.023. Epub 2012 Jul 24. 
[19] K.M.Z. Hossain, U. Patel, A.R. Kennedy, L. Macri-Pellizzeri, V. Sottile, D.M. Grant, B.E. Scammell, I. Ahmed, Acta biomaterialia, 72 (2018) 396-406.

[20] P.F. Lee, X. Zhang, D.D. Sun, J. Du, J.O. Leckie, Colloids and Surfaces A: Physicochemical and Engineering Aspects, 324 (2008) 202-207.

[21] A. Matamoros-Veloza, K.M.Z. Hossain, B.E. Scammell, I. Ahmed, R. Hall, N. Kapur, Journal of the Mechanical Behavior of Biomedical Materials, 102 (2020) 103489.

[22] K.M.Z. Hossain, U. Patel, I. Ahmed, Progress in biomaterials, 4 (2015) 1-19.

[23] Y. Cai, Y. Chen, X. Hong, Z. Liu, W. Yuan, International journal of nanomedicine, 8 (2013) 1111.

[24] S. Freiberg, X. Zhu, International journal of pharmaceutics, 282 (2004) 1-18.

[25] S. Li, L. Nguyen, H. Xiong, M. Wang, T.C.C. Hu, J.X. She, S.M. Serkiz, G.G. Wicks, W.S. Dynan, Nanomedicine: Nanotechnology, Biology and Medicine, 6 (2010) 127-136.

[26] R. Perez, A. El-Fiqi, J.H. Park, T.H. Kim, J.H. Kim, H.W. Kim, Acta biomaterialia, 10 (2014) 520530.

[27] D. Arcos, A. López-Noriega, E. Ruiz-Hernandez, O. Terasaki, M. Vallet-Regi, Chemistry of Materials, 21 (2009) 1000-1009.

[28] B. Lei, X. Chen, Y. Wang, N. Zhao, G. Miao, Z. Li, C. Lin, Materials Letters, 64 (2010) 22932295.

[29] M.T. Islam, K.M.Z. Hossain, N. Sharmin, A.J. Parsons, I. Ahmed, International Journal of Applied Glass Science, 8 (2017) 391-402.

[30] R. Harrison, H. Markides, R.H. Morris, P. Richards, A.J. El Haj, V. Sottile, Journal of tissue engineering and regenerative medicine, 11 (2017) 2333-2348. 
[31] D. Gupta, D.M. Grant, K.M. Zakir Hossain, I. Ahmed, V. Sottile, J Biomater Appl, 32 (2018) 906-919.

[32] H. Giesche, Particle \& particle systems characterization, 23 (2006) 9-19.

[33] N.J. Lakhkar, J.-H. Park, N.J. Mordan, V. Salih, I.B. Wall, H.-W. Kim, S.P. King, J.V. Hanna, R.A. Martin, O. Addison, Acta biomaterialia, 8 (2012) 4181-4190.

[34] A. Al-Noaman, S.C. Rawlinson, R.G. Hill, Journal of Non-Crystalline Solids, 358 (2012) 30193027.

[35] M.T. Islam, N. Sharmin, G.A. Rance, J.J. Titman, A.J. Parsons, K.M.Z. Hossain, I. Ahmed, Journal of Biomedical Materials Research Part B: Applied Biomaterials, (2019).

[36] S. Maeno, Y. Niki, H. Matsumoto, H. Morioka, T. Yatabe, A. Funayama, Y. Toyama, T. Taguchi, J. Tanaka, Biomaterials, 26 (2005) 4847-4855.

[37] S. Yoshizawa, A. Brown, A. Barchowsky, C. Sfeir, Connective tissue research, 55 (2014) 155159.

[38] M. Julien, S. Khoshniat, A. Lacreusette, M. Gatius, A. Bozec, E.F. Wagner, Y. Wittrant, M. Masson, P. Weiss, L. Beck, Journal of Bone and Mineral Research, 24 (2009) 1856-1868.

[39] D. Hamasaki, The Journal of physiology, 167 (1963) 156-168.

[40] W. Habraken, P. Habibovic, M. Epple, M. Bohner, Materials Today, 19 (2016) 69-87.

[41] M. Bohner, Eur Cell Mater, 20 (2010) 3-10.

[42] E.D. Eanes, Amorphous calcium phosphate: thermodynamic and kinetic considerations, Calcium phosphates in biological and industrial systems, Springer, 1998, pp. 21-39.

[43] X. Hu, S.H. Park, E.S. Gil, X.X. Xia, A.S. Weiss, D.L. Kaplan, Biomaterials, 32 (2011) 8979-8989. 
[44] G. Abagnale, M. Steger, V.H. Nguyen, N. Hersch, A. Sechi, S. Joussen, B. Denecke, R. Merkel, B. Hoffmann, A. Dreser, U. Schnakenberg, A. Gillner, W. Wagner, Biomaterials, 61 (2015) 316326.

[45] A.C. Tsai, Y. Liu, X. Yuan, T. Ma, Tissue engineering. Part A, 21 (2015) 1705-1719.

[46] P. Valerio, M.M. Pereira, A.M. Goes, M.F. Leite, Biomaterials, 25 (2004) 2941-2948.

[47] S. Maeno, Y. Niki, H. Matsumoto, H. Morioka, T. Yatabe, A. Funayama, Y. Toyama, T. Taguchi, J. Tanaka, Biomaterials, 26 (2005) 4847-4855.

[48] C.B. Danoux, D.C. Bassett, Z. Othman, A.I. Rodrigues, R.L. Reis, J.E. Barralet, C.A. van Blitterswijk, P. Habibovic, Acta Biomater, 17 (2015) 1-15.

[49] A.M. Barradas, H.A. Fernandes, N. Groen, Y.C. Chai, J. Schrooten, J. van de Peppel, J.P. van Leeuwen, C.A. van Blitterswijk, J. de Boer, Biomaterials, 33 (2012) 3205-3215.

[50] S. Yoshizawa, A. Brown, A. Barchowsky, C. Sfeir, Acta Biomater, 10 (2014) 2834-2842.

[51] S. Yoshizawa, A. Brown, A. Barchowsky, C. Sfeir, Connect Tissue Res, 55 Suppl 1 (2014) 155159.

[52] J.R. Tse, A.J. Engler, PLoS One, 6 (2011) e15978.

[53] A. Shekaran, E. Sim, K.Y. Tan, J.K. Chan, M. Choolani, S. Reuveny, S. Oh, BMC Biotechnol, 15 (2015) 102.

[54] E.A. Abou Neel, T. Mizoguchi, M. Ito, M. Bitar, V. Salih, J.C. Knowles, Biomaterials, 28 (2007) 2967-2977.

[55] W. Xue, K. Dahlquist, A. Banerjee, A. Bandyopadhyay, S. Bose, J Mater Sci Mater Med, 19 (2008) 2669-2677. 
[56] S. Sista, A. Nouri, Y. Li, C. Wen, P.D. Hodgson, G. Pande, J Biomed Mater Res A, 101 (2013) 3416-3430.

[57] H.M. Hu, L. Yang, Z. Wang, Y.W. Liu, J.Z. Fan, J. Fan, J. Liu, Z.J. Luo, Int J Clin Exp Pathol, 6 (2013) 841-852.

[58] I. Ahmed, S. Shaharuddin, N. Sharmin, D. Furniss, C. Rudd, Biomedical glasses, 1 (2015). 